


\title{
School Selectivity, Peers, and Mental Health
}

\author{
Aline Bütikofer* $\quad$ Rita Ginja $^{\dagger} \quad$ Fanny Landaud $^{\ddagger} \quad$ Katrine V. Løken $\rrbracket^{\S}$
}

October 14, 2020

\begin{abstract}
Although many students suffer from anxiety and depression, and students often identify school pressure and concerns about their futures as the main reasons for their worries, little is known about the consequences of a selective school environment on students' physical and mental health. In this paper, we draw on rich administrative data and the features of the high school assignment system in the largest Norwegian cities to consider the long-term consequences of enrollment in a more selective high school. Using a regression discontinuity analysis, we show that eligibility to enroll in a more selective high school increases the probability of enrollment in higher education and decreases the probability of diagnosis or treatment by a general medical practitioner for psychological symptoms and diseases. We further document that enrolling in a more selective high school has a greater positive impact when there are larger changes in the student-teacher ratio, teachers' age, and the proportion of female teachers. These findings suggest that changes in teacher characteristics are important for better understanding the effects of a more selective school environment.
\end{abstract}

\footnotetext{
*Department of Economics, Norwegian School of Economics, Helleveien 30, 5045 Bergen, Norway; IZA; email: Aline. Buetikofer@nhh.no.

†Department of Economics, University of Bergen, Fosswinckelsgate 14, 5007 Bergen, Norway; Institute for Fiscal Studies; IZA; email: rita.ginja@uib.no.

${ }^{\ddagger}$ Department of Economics, Norwegian School of Economics, Helleveien 30, 5045 Bergen, Norway; IZA; email: Fanny. Landaud@nhh.no.

${ }^{\S}$ Department of Economics, Norwegian School of Economics, Helleveien 30, 5045 Bergen, Norway; IZA; email: Katrine. Loken@nhh.no.

IWe are grateful for comments by Éric Maurin and Edwin Leuven. We also thank seminar, workshop, and conference participants at the Paris School of Economics, Statistics Norway, Tilburg University, University of Rotterdam, the University of Essex, the University of Gothenburg, the Swedish Institute for Social Research, Instituto de Ensino e Pesquisa (Insper), and the 2020 NBER Summer Institute. Maria Køber Guldvik provided excellent research assistance. This work was partially supported by the Research Council of Norway through its Centres of Excellence Scheme, FAIR project No 262675 and by the NORFACE DIAL grant 462-16-050.
} 


\section{Introduction}

Depression and anxiety are among the leading causes of illness and disability among adolescents (WHO, 2019). For instance, roughly one in three high school students in the US report suffering from depression or anxiety symptoms in a given year (HHS, 2017). Adolescent mental illness is also widespread in countries that conventionally rank among the happiest countries according to the World Happiness Report. In Norway, for example, $22 \%$ of high school students report depression or anxiety issues (Ungdata, 2018). This is important because mental health problems among adolescents are associated with various costly long-term outcomes such as lower labor market productivity, less marriage stability, and other adult health problems (Currie et al., 2010; Goodman et al., 2011; Lundborg et al., 2014).

Survey evidence indicates that school pressure is one of the main causes of adolescent worries (see e.g., Eriksen et al., 2017). However, we know little about the relationship between the school environment, and in particular school selectivity, and adolescent mental health. As it stands, the potential effects of school selectivity on mental health are ambiguous. On the one hand, a selective school, with more high-ability peers, might be a more stressful experience negatively affecting student mental health. On the other hand, peers at more selective schools may have different health care usage and display better health behaviors such as lower smoking rates or greater physical activity. Moreover, enrolling in a more selective school could result in different teacher characteristics and may be an inspiring experience that opens up new perspectives. This could positively influence student aspirations and mental health in both the short and long term. Because common determinants likely influence student choice of enrolling in a more selective high school and student health and health behaviors, and because data linking detailed school and health outcomes are not easily available, evidence on the causal effects of the school environment on student mental health remains very scarce.

This paper overcomes these identification and data challenges, providing new insights into how high school selectivity affects mental health. First, to overcome the identification problem, we build on the features of the high school assignment system in the two largest Norwegian cities, which assign students to high schools through a centralized process giving priority to students with the best average grades in middle school. This assignment system enables a regression discontinuity analysis, where we compare the long-term outcomes of students that are very similar at the end of middle school but are eligible to enroll in less or more selective high schools. Second, we link several administrative data sources, including information about 
educational institutions and school grades, as well as health care take-up, and create a long panel allowing us to document the effects on outcomes during and beyond high school.

The available data also enable us to characterize the features of a more selective school environment with respect to peer and teacher characteristics, school size, and the number of students per teacher. These features may differ across countries and contexts and are therefore important to consider. Abdulkadiroğlu et al. (2014), for example, demonstrate that going to an exam school in Boston implies going to a school with higher-achieving peers, fewer Black and Hispanic students, more experienced teachers, and larger class sizes. In the context of Romania, Pop-Eleches and Urquiola (2013) also find variations in teacher characteristics across selective schools. In France, where the central administration attempts to equalize resources across schools, Landaud et al. (2018) reveal little variation in teacher characteristics or class sizes across selective Parisian high schools, despite large variation in student ability. Beyond documenting the implications of enrolling in a more selective high school in terms of peers, teachers, and other school features, we make use of the fact that we have variation in which of these school inputs changes more when enrolling in a more selective high school and implement a heterogeneity analysis. In essence, we estimate our regression discontinuity model for each of the 84 admission thresholds and each school feature separately and estimate whether changes in longer-term outcomes are greater when students gain eligibility to schools where peer and teacher characteristics or school resources change by a larger margin at the admission thresholds.

We present four key findings. First, we find that students that are eligible to enroll in a more selective high school are 8.3 percentage points more likely to enroll in the more selective school. Further, we show that eligibility to enroll in a more selective high school increases the likelihood of high school completion by 2.3 percentage points $(4.2 \%)$ and the likelihood of enrollment in higher education by 1.6 percentage points $(4.0 \%)$. Students gaining access to the most selective schools in our sample mostly drive these improvements in educational outcomes. Second, we document that eligibility to enroll in a more selective school does not affect the use of primary care services up to six years after high school completion but does decrease the likelihood of diagnosis or treatment for mental health issues. In particular, we estimate that eligibility for enrollment in a more selective school reduces the likelihood of mental health diagnosis or treatment (driven by a reduction in anxiety and depression) by 1.7 percentage points (5.2\%). In particular, we conclude that female students and students gaining access to the most selective schools drive these estimated effects, whereas the mental health of male students is largely unaffected. Hence, our findings indicate that eligibility for enrollment in a more selective school is protective of the mental health of girls. Third, we investigate 
what features of the school environment change at the threshold. We document that eligibility for enrollment in a more selective high school significantly changes the ability level of peers, peers' parental education and income, the number of students per teacher, and the share of female teachers. Lastly, our heterogeneity analysis suggests that changes in teacher characteristics—and not necessarily peer characteristics—could be important for explaining our main findings. Taken together, our findings provide key implications for ongoing policy debate over the consequences of school selectivity and the role of school inputs for student educational and health outcomes.

This paper particularly contributes to the literature on the relationships between education and health and school selectivity. Most empirical research identifying the causal effects of education on physical or mental health exploits exogenous variations from compulsory schooling reforms, regulations on school starting age, or school tracking (see, e.g., Böckerman et al., 2019; Clark and Royer, 2013; Crespo et al., 2014; Dursun and Cesur, 2016; Lager et al., 2016; Lleras-Muney, 2005; Meghir et al., 2018). We expand this literature by moving beyond changes in compulsory education, which mostly target individuals at the lower end of the educational distribution, and analyze the extent to which the high school environment links to health. Because the selectivity of higher education institutions correlates with student mental health and wellbeing (Fletcher and Frisvold, 2011, 2014; Frisvold and Golberstein, 2011), it is important to understand better the effect of high school selectivity, as well as the influence of high school peers, teachers, and financial resources on student health. Establishing this link is crucial for education policies aiming at improving the learning environment for students to increase their long-term welfare.

In addition, this paper complements the growing literature on the consequences of school selectivity (see e.g., Abdulkadiroğlu et al., 2017, 2014; Clark and Del Bono, 2016; Cullen et al., 2006; Dobbie and Fryer Jr, 2014; Jackson, 2013; Landaud et al., 2018; Pop-Eleches and Urquiola, 2013). ${ }^{1}$ First, we expand the set of outcomes by studying the effects on health and educational outcomes after high school to provide a more complete longer-term picture of the effects of a more selective school environment. Our second contribution concerns the mechanisms behind the estimates. We combine a unique setting of 84 different school admission thresholds with detailed information on several school inputs (characteristics of peers, teachers, school size, and the number of students per teacher) to investigate which features of a more selective school environment may help explain our findings. Understanding the role of school inputs for educational outcomes or mental

\footnotetext{
${ }^{1}$ Note that our paper mostly relates to studies on selectivity in the context of nonelite schools. In our setting, school admission cutoffs are located between the $4^{\text {th }}$ and the $97^{\text {th }}$ percentile of the test score distribution after middle school in the areas of interest and on average located around the $40^{\text {th }}$ percentile.
} 
health is important for explaining in what context selectivity matters. This could help reconcile why selective schools have negative or no effects in some contexts and positive effects in others.

\section{Institutional Context}

\subsection{The Norwegian School System}

The Norwegian education system consists of four levels: primary school (grades 1-7), middle school (grades 8-10), high school with academic (grades 11-13) and vocational (grades 11-14) tracks, and college and university education. Norwegian compulsory education starts at age six years, lasts for 10 years, and consists of primary and middle school. Compulsory schooling is organized by Norwegian municipalities and the vast majority (98\%) of pupils attend local public schools. The curriculum is identical in all primary and middle schools, there is no streaming by ability, and all pupils are allocated to schools based on fixed school catchment areas within municipalities.

While there are no grades in primary school, the school system becomes more competitive from middle school onward, where exit exams and teacher grades are crucial for admission into the best high schools. At the end of grade 10, all students obtain a diploma with a total grade point average (hereafter, middle school GPA). This is the weighted total of all teacher-awarded grades, combined with the grades from written and oral exams in randomly drawn subjects. ${ }^{2}$ The middle school GPAs possible range is from zero to 60 , where 60 is the best possible grade. Assignment to high schools varies across counties. ${ }^{3}$ The two largest cities in Norway-Oslo and Bergen—have varied their intake systems over recent years. In this paper, we consider those years where they followed a free school choice system with a centralized intake based on the middle school GPA. That is, we study enrollment in general study programs in high schools located in Bergen from 2006 to 2010 and in Oslo from 2009 to 2010.

In contrast to the compulsory middle schools, enrollment in high schools is voluntary. Nevertheless, all students aged 16 to 23 years in Norway have a statutory right to enrollment at this level. However, this right is at the county level and does not ensure enrollment in a specific school or program. First time enrollment in high school in Norway is high: $98 \%$ of students enroll in the first year. Students enroll either in general studies

\footnotetext{
${ }^{2}$ The subjects of the teacher-awarded grades are written (two courses) and oral Norwegian, written and oral English, mathematics, nature and science, social sciences, religion, home economics, physical education, music, and arts and craft.

${ }^{3}$ Twelve of the 19 counties in Norway had a free school choice system in 2016. In rural counties, geographic criteria still largely determine student high school choice.
} 
$(50 \%)$, in vocational programs $(45 \%)$, or in alternative training plans $(3 \%)$. There is, however, considerable dropout in the second and third years: only $80 \%$ of students initially enrolled in general studies programs graduate. Graduation rates for vocational programs are even lower. Graduating in general studies provides students with the required qualifications for enrollment in higher education, while students graduating in the vocational track need to spend an additional year of study before reaching similar qualifications.

Although high school ranks are not important for access to higher education, high school grades and national exams at the end of high school determine access to higher education. In Norway, the intake to public higher education follows a centralized admission system based on total grade points from high school (hereafter, high school GPA). For those graduating high school with a general studies degree, about $40 \%$ do not enroll in any general higher education program.

\subsection{High Schools in Oslo and Bergen}

There are 15 public high schools in Bergen offering general education programs and 20 in Oslo. For Bergen, we focus on the five cohorts of students completing middle school between 2006 and 2010. For Oslo, we consider the two cohorts of students completing middle school between 2009 and $2010 .{ }^{4}$ During these periods, assignment to general programs in high school worked through a centralized system where students ranked schools and education programs, and were then assigned based on their ranked-ordered list and middle school GPA. Students could rank up to six different schools for enrollment in general studies. The key feature of this assignment system is that there is a minimum admission score for enrollment in general studies for each oversubscribed high school. Oversubscribed high school are high schools that receive more applications than they can accommodate. In the years we study, the majority of high schools in Bergen and Oslo were oversubscribed for enrollment in general studies, and we observe significant discontinuities in the rate of enrollment of students at specific cutoff points of the distribution of middle school GPA. This feature makes it possible to implement a regression discontinuity analysis to assess the effect of enrollment in general education programs in more or less selective high schools on subsequent health and educational outcomes.

To help with interpretation, we now briefly describe the Oslo and Bergen high schools. We focus on how they are similar and how they differ along key dimensions, such as peer and teacher quality and financial

\footnotetext{
${ }^{4}$ The health data we are using covers the years 2006-2016 which is why we start with the graduating cohort of 2006 in Bergen. For Oslo, we start in 2009 because high school assignment was based on geographical criteria rather than on the middle school GPA for the graduating cohorts between 2006 and 2008.
} 
resources. High schools in Oslo and Bergen have on average about 540 students per school, and there are about 15 students per teacher. Resources for high schools are centrally allocated and based on the numbers of students, and there is variation across schools in both financial and teacher resources. For example, the top quartile of schools in terms of the students to teacher ratio has just nine students per teacher, while the lowest quartile of schools have 19.8. ${ }^{5}$ Similarly, the top quartile of schools in terms of teacher diploma have about $65 \%$ of teachers with a master's degree, while the lowest quartile of schools have none. Another key difference across high schools is student ability. The top quartile of schools in terms of student ability have students with an average middle school GPA of 50, while the lowest quartile of schools has students with an average GPA of 37.7 .6 Because middle school GPA is correlated with gender and family background, we also observe significant differences in average student characteristics across high schools. Finally, all general programs offer compulsory core curriculum subjects like languages, natural sciences, and human sciences, but there is greater variety across schools in the availability of more specialized subjects like music, media, arts, and sports.

In section 5, we document how school characteristics vary on average at the admission thresholds and leverage this information on differences in school inputs at the thresholds to provide insights into what school characteristics may explain the average effects on health and education.

\subsection{Health Services in Norway}

In Norway, health services are publicly financed and universally accessible for all Norwegian citizens. The services are organized in two levels: primary care and specialist care. Primary health care is the responsibility of the municipalities and includes general practitioners, emergency rooms, infant and child health care centers, school health services, and elderly care. Specialist care is the responsibility of the four health regions in Norway and it includes somatic specialist care, psychiatric health services, and private referral specialists.

Primary and Specialist Health Services. General practitioners (hereafter GPs) and local emergency rooms (hereafter ERs) are the basis of the primary care services. The vast majority of Norwegian citizens

\footnotetext{
${ }^{5}$ Note that the students to teacher ratio does not necessarily reflect classroom size, rather the variety of teachers employed by the school given we measure the number of teachers employed at each school rather than the number of full-time positions.

${ }^{6} \mathrm{~A}$ middle school GPA of 50 or 37.7 corresponds to the $83^{\text {rd }}$ percentile or the $35^{\text {th }}$ percentile of the distribution of middle school GPA, respectively.
} 
belong to a specific GP's list, and GPs are responsible for providing primary health care services to the patients on their list. GPs diagnose their patients, certify sick leave, prescribe treatments, and refer their patients to specialist care when needed. They also follow up on their patient after they have received care in the specialist system. In general, the GPs serve as gatekeepers to the specialist care system and health-related welfare benefits.

Most specialist care is provided through public hospitals and outpatient care clinics, but contracted private specialists can also provide specialist care. In general, the first contact with specialist care takes place via the referral of the patient by the GP or the ER because it is not possible for a patient to proceed directly to specialist care within the public health system.

School Health Services. All Norwegian school children and youth are entitled to vaccinations, health education, and guidance, as well as medical examinations and access to health care professionals when needed (Helse- og omsorgsdepartementet, 2003). For school-age children, these are responsibilities of the school health services. ${ }^{7}$ School health care services are easily accessible to students and are free of charge. These services are available at school premises during school hours and primarily provided by school nurses. School nurses are employed by municipalities and not by schools and may provide services to more than one school simultaneously. Importantly, the school health services are preventive. For curative purposes, the children are referred to primary or specialist care services (Helsetilsyn, 1998). One exception is that school nurses are entitled to prescribe birth control pills (free of charge) to young women aged 16-19 years.

There is no systematic registry of the actual use of school health services by students (Abrahamsen et al., 2019). Survey information from 2013 shows that about $25 \%$ of the students in high school use school health services at least once a year (Bakken, 2018). However, there are substantial gender differences in use: only about $13 \%$ of high school boys consult school nurses at least once a year, but $35 \%$ of high school girls. The most common reason for using school health services during high school are matters regarding sexuality and contraception.

\footnotetext{
${ }^{7}$ Younger children receive these services in child health care centers that also provide pre- and postnatal services for mothers and newborns.
} 


\section{Data and Empirical Strategy}

\subsection{Data}

The data for this paper is compiled from several Norwegian administrative records, including the national educational registers, tax records, family registers, and health registers. We consider the sample of students that completed $10^{\text {th }}$ grade between 2006 and 2010 in Bergen and in 2009 or 2010 in Oslo. In total, our sample comprises 19,932 individuals attending 87 different middle schools.

\subsubsection{Demographic and Socioeconomic Information}

The demographic and socioeconomic information is from registers covering the entire resident population in Norway up to 2014, which includes information such as the year and month of birth, gender, immigration status, municipality of residence in each year, and highest educational attainment. Information on earnings is from the tax registers. All registers include unique identifiers, and the population register specifies unique identifiers for the parents of each individual. This enables us to recover for each individual and his/her parents all relevant socioeconomic information. ${ }^{8}$

\subsubsection{Schools and Educational Data}

Information on enrollment in middle school, high school, and university is from the national educational registers and is available up to 2014. For each individual in our sample, we observe the middle and high schools attended, as well as the track in which the student enrolled, and the degrees, if any, completed. Educational choices and attainments are reported by the schools directly to Statistics Norway, thereby minimizing any measurement error from misreporting. For each student, we also observe the $10^{\text {th }}$ grade GPA and the GPA upon completion of high school. Finally, these registers contain information about whether individuals enrolled in college up to four years after completion of middle school, including those who enroll in college immediately after graduating from high school or following a gap year.

For each high school, we have information about its staff from the Social Security records. This information allows us to construct proxies for teacher quality and school financial resources. In particular, we specify variables indicating the share of teachers with a master's degree, the average age of teachers,

\footnotetext{
${ }^{8}$ Both parental income and education are measured when students complete grade 10. For parental income, we specify the sum of the earnings of the mother and father. For parental education, we create an indicator variable taking a value of one if at least one parent completed a higher education degree.
} 
the proportion of female teachers, students per teacher, students per non-educational staff, and the number of students per program. We also use information on student characteristics and high school enrollment to construct variables indicating for each student the average characteristics of peers in high school, such as the middle school GPA of peers, gender, parental education, and parental income.

\subsubsection{Health Data}

Information on visits to GPs and ERs is from the Control and Payment of Health Refunds database (acronym KUHR in Norwegian), which is available between 2006 and 2016. GPs and ERs are obliged to report all consultations and relevant International Classification of Primary Care (ICPC-2) codes to this national claims database to receive payment. ICPC codes convey information about the GPs' assessment of the patient's health problems and the type of care provided. Specifically, each ICPC code is made of one letter, indicating where the symptoms or diseases are located in the body, and two numbers indicating whether the GPs assessed health symptoms, diseases, prescribed a screening or preventive procedure, prescribed medication or treatments, analyzed test results, or performed an administrative task. ${ }^{9}$

Using this information, we constructed variables indicating whether and how many times each student visited a GP or ER between middle school completion and up to six years later, that is during the three years of high school and the first three post-high school years. In addition, as a selective school environment may have specific impacts on mental health issues, we constructed for each student a variable indicating whether during any consultation a GP assessed psychological symptoms or disease (ICPC codes beginning with the letter "P"). ${ }^{10}$ When constructing these variables, we consider academic rather than calendar years, that is, we consider for each year $t$ visits between August $t$ and July $t+1$.

\subsection{Cutoff Admission Scores}

Our data provide detailed information on student demographic characteristics, school environment, health, and education. However, we do not have information on student applications to and rankings of high schools. As a result, it is not possible directly to identify high school admission thresholds from the data. ${ }^{11}$

\footnotetext{
${ }^{9}$ See Appendix B for the list of ICPC-2 codes.

${ }^{10}$ Note that we do not know whether students are diagnosed or treated for a psychological issue for the first time because we only observe GP and ER visits since 2006.

${ }^{11}$ Unlike admissions to universities, which follow a nationwide assignment mechanism used in Kirkeboen et al. (2016), at high school level the admission system is decentralized at the county level. Unfortunately, we do not have information on student applications in these decentralized systems.
} 
We, therefore, build on the methodology in Hansen (2000) to overcome this issue. This method was recently used by Hoekstra (2009) to identify admission thresholds and estimate the effect of going to a flagship university in the US and by Landaud et al. (2018) to study the effect of enrollment in selective Parisian high schools. ${ }^{12}$ In addition, Porter and Yu (2015) show that this procedure can be used in combination with a standard regression discontinuity (RD) analysis without further adjustment or assumptions. In short, we identify schools for which there exists a significant positive discontinuity in enrollment rates and the procedure selects for each school the threshold that minimizes the number of incorrectly assigned students (i.e., enrolled students below the threshold or unenrolled students above the threshold).

In practice, for each cohort and high school in Bergen, we focus on the sample of $10^{\text {th }}$ graders in Hordaland county (the county where the city of Bergen is located). For high schools in Oslo, we consider the sample of $10^{\text {th }}$ graders in Oslo county. For each value $g$ of the $10^{\text {th }}$ grade GPA score distribution, we define a dummy which takes a value of one if student's $i$ score, $f_{i}$, is greater than or equal to the cutoff score $g, D_{i}^{g}=1\left[f_{i} \geq g\right]$. For each high school $z$ in year $t$, we estimate the following regression for each value $g$ (omitting subscript $t$ ):

$$
E_{i z}=\alpha+\psi_{z} D_{i}^{g}+\varepsilon_{i z}
$$

where $E_{i z}$ takes a value of one if student $i$ enrolls in high school $z$ in year $t$, and zero otherwise. For each high school $z$ in year $t$, we select as admission cutoff, $f_{z}$, the value of the $10^{\text {th }}$ grade GPA score $g$ that maximizes the $R^{2}$ of equation (1) with a significantly positive $\hat{\psi}_{z}$. Further, we exclude a few admission thresholds with very small estimated discontinuities in enrollment rates around these cutoffs. ${ }^{13}$ For each oversubscribed high school $z$, we then define the subsample of $10^{\text {th }}$ graders whose middle school is located within eight kilometers of $z .^{14}$ Then, for each student, we define his/her GPA score-distance $f_{i}-f_{z}$ to the cutoff admission score of high school $z$, and we use regression discontinuity analysis where we pool all subsamples of students and

\footnotetext{
${ }^{12}$ This approach has also been used in other settings, such as testing for discontinuities in the dynamics of neighborhood racial composition (see e.g., Card et al., 2008), or evaluation of social programs (see e.g., Carneiro et al., 2019).

${ }^{13}$ From the 105 estimated cutoffs, we exclude 21 with estimated discontinuities in enrollment rates below 0.015 percentage points, obtaining 84 oversubscribed high schools during the period of interest. In detail, we obtain 11 oversubscribed high schools in Bergen in 2006, 2008, and 2010, 10 in 2007, and 12 in 2009. For Oslo, we obtain 14 oversubscribed high schools in 2009 and 15 in 2010. Within each city and year, the admission cutoffs vary on average by two points between every two high schools of adjacent selectivity level.

${ }^{14}$ We use this criterion to maximize our first stage results because Fack et al. (2019) provide evidence that geographical proximity is a strong driver of student preferences over high schools. In addition, about $90 \%$ of students graduating from middle schools located in Bergen or Oslo during the years of interest and enrolled in general studies went to high schools located within eight kilometers of their middle school. The results are robust with respect to longer or smaller distance criteria when constructing the working sample.
} 
use $f_{i}-f_{z}$ as a running variable.

\subsection{Empirical Approach}

To estimate the effects of a more selective school environment, following Lee and Lemieux (2010), we implement a standard regression discontinuity analysis where we compare students whose middle school GPA fell either just above or below the admission threshold of an oversubscribed high school. For each educational or health outcome $Y_{i}$ in our data, we start by estimating the following model (omitting subscript $t)$ :

$$
Y_{i}=\delta+\alpha \mathbb{1}\left\{f_{i}-f_{z} \geq 0\right\}+\eta\left(f_{z}-f_{i}\right)+\lambda\left(f_{i}-f_{z}\right) \times \mathbb{1}\left\{f_{i}-f_{z} \geq 0\right\}+X_{i} \gamma+\omega_{z}+u_{i},
$$

where $f_{i}-f_{z}$ measures the distance in points between school $z$ 's admission threshold and student $i$ 's middle school GPA. $X_{i}$ is a set of control variables, which includes student age, gender, family background, and average GPA in grade 10 in mathematics and Norwegian. We also include as control variables a full set of cutoff dummies, $\omega_{z}$, and $u_{i}$ represents the unobserved determinants of student health and education. Under the maintained assumption that there is no discontinuity in the distribution of $u_{i}$ at the cutoffs, the parameter $\alpha$ can be interpreted as the causal effect of eligibility for admission in a more selective high school on the outcome $Y_{i}$. The standard errors are clustered at the individual level, and we exclude students whose middle school GPA fell within 0.1 points of the admission thresholds from the analysis to avoid measurement error issues due to estimated cutoffs. We follow Calonico et al. (2014) to choose an optimal bandwidth around admission thresholds, which is 5.19 points. Finally, we use a triangular kernel centered on the admission cutoffs. In the following sections, we show that our results are robust to alternative functional forms, bandwidths, and sets of control variables.

Because we study the effects on a relatively large number of potentially correlated outcomes, we test which of the estimated impacts survive adjustment for multiple hypothesis testing. We use the procedure in algorithms 4.1 and 4.2 of Romano and Wolf (2005), which account for testing several hypotheses simultaneously. Romano and Wolf (2005) propose an iterative rejection/acceptance procedure for a fixed level of significance. We use 1,000 block-bootstrap replications to obtain the adjusted critical values (the block is the individual). The result tables indicate whether the coefficients remain significant at a level of 1,5 , or 10 percent after using this procedure. 
In our context, the mapping from eligibility to enrollment is not one-to-one because students may not effectively enroll in the high schools for which they are eligible due to, for example, preferences for other programs or locations. Therefore, we present instrumental variable (IV) estimates where enrollment in a given selective high school is instrumented with eligibility for enrollment in this high school (Hahn et al., 2001). Note that these results should be interpreted cautiously because IV requires that the exclusion restriction and monotonicity hold. ${ }^{15}$ Eligibility for a more selective school increases enrollment to a preferred school, but could also have indirect effects via changes in psychological factors such as aspirations and disappointment. We provide suggestive evidence that this is unlikely to be a major factor in that the estimated effects on mental health appear mostly after high school, and thus do not reflect the mere short-term effect of enrolling (or failing to enroll) in a preferred school. We also emphasize that we estimate the IV on a set of compliers that may have different characteristics than the average students at the thresholds.

Descriptive Statistics. Table A1 provides descriptive statistics for the students in our working sample. For the sake of comparison, the table includes three samples: all students completing $10^{\text {th }}$ grade in Norway between 2006 and 2010, students completing $10^{\text {th }}$ grade in the county of Hordaland (where the city of Bergen is located) between 2006 and 2010 and in Oslo in 2009 and 2010, and our regression discontinuity sample. The main takeaway is that the average student in Hordaland or Oslo (Column (3)) is comparable to our RD sample of students (Column (5)). However, when compared with the average student in Norway (Column (1)), we can see that students in Oslo and Bergen are positively selected on educational outcomes and demographic characteristics. For example, students in Oslo and Bergen area in our RD sample specialize more often in the general education track compared with the average student in Norway. In addition, these students have better-off peers with higher middle school GPAs. They are also more likely to graduate from high school and enroll in higher education up to four years after commencing high school. Interestingly, students in Oslo and Bergen and our RD sample are as likely to visit a GP or an ER as the average student completing $10^{\text {th }}$ grade in Norway. There are also no differences in the use primary health care services or likelihood of being diagnosed or treated by GPs for mental health problems.

In section 4, we present the results for the RD sample, and, in addition, separately by the level of school selectivity, where schools with high (low) selectivity levels are schools whose admission threshold fell in the

\footnotetext{
${ }^{15}$ Violations of the monotonicity assumption are unlikely in our setting because this would mean that students eligible to enroll in a more selective school are less likely to enroll in the more selective school compared with the lower-ranked school. In addition, strong first stages (results available upon request) across subgroups support the monotonicity assumption.
} 
top (bottom) half of the distribution of cutoffs by city and year.

\subsection{Tests of Identifying Assumptions}

Students just above and below the cutoffs differ in their eligibility to enroll in a more selective high school, but we assume that they are similar in all other (observable and unobservable) predetermined dimensions. Below, we present evidence for the validity of our identification assumption.

Strategic Manipulation around Cutoff. One threat to identification would be that students willing to enroll in specific high schools manage to earn a score just above the admission thresholds. To provide empirical evidence that there is no strategic manipulation of the running variable at the cutoffs, Figure A1 presents the results when implementing the density tests suggested in McCrary (2008) on the full sample and separately by selectivity level. The panels in the figure illustrate that the density of the running variable is continuous at the cutoffs for the three samples, providing evidence supporting our identifying assumption.

Covariate Balance. Further, to assess the validity of our identification assumption of no discontinuity in unobserved determinants of students' health and education at the cutoffs, Table A2 reports the results of estimating model (2) using student baseline characteristics such as gender, nationality, and parental background as dependent variables. ${ }^{16}$ Consistent with our identification assumption, we do not observe systematic discontinuities in the predetermined characteristics of students whose middle school GPA fell just above or below the admission threshold of an oversubscribed high school. This is shown in Figure A2 in the Appendix including the corresponding graphical estimates of model (2), excluding controls $X_{i}$ and $\omega_{z}$, for the three samples we examine. The last row of each panel in Table A2 presents the $F$-test of joint significance obtained from regressing the eligibility dummy $\mathbb{1}\left\{f_{i}-f_{z} \geq 0\right\}$ on the full set of baseline variables. The $F$-tests presented in each panel suggest that there is no systematic manipulation around the cutoff because they do not reject the null hypothesis that the coefficients are jointly equal to zero.

The finding that student characteristics are continuous around admission thresholds is not very surprising in the setting we consider in that school admission cutoffs are ex ante impossible to predict precisely or manipulate. On average, school admission thresholds vary by 3.4 points from one year to the next, and they

\footnotetext{
${ }^{16}$ When estimating model (2) for balancing tests, we include a full set of cutoff/year dummies as control variables but do not control for student baseline characteristics.
} 
are jointly determined by the preferences and middle school GPAs of all $10^{\text {th }}$ graders in Hordaland or Oslo, which are unknown at the time of application.

Note that the results reported in Table A2 and Figure A2 do not rule out that the average ability of student peers varies discontinuously at the thresholds, along with other characteristics of peers and the school environment. For example, a more selective school might be able to attract better teachers. In section 5, we discuss this in detail and attempt to quantify whether the changes in a high school's environment at the cutoff explains the effects of enrollment in a more selective high school on student education and health.

\section{Empirical Results}

In this section, we first investigate how eligibility for enrollment in a more selective school affects actual enrollment. We then turn to consider the impacts on subsequent education and health.

\subsection{First Stage Results}

Figure 1 presents our first stage results, that is, the effect of eligibility for enrollment in a more selective school on actual enrollment in this high school. For each figure, the solid lines plot the fitted regression lines after estimating model (2) without controls for student baseline characteristics or cutoff dummies (i.e., $X_{i}$ and $\omega_{z}$ ). The plotted points are the conditional means of the dependent variable for students in a one-unit binwidth. At the top of each figure, we report the estimated $\alpha$, which is the estimated effect of eligibility for enrollment in a more selective high school on actual enrollment, and its standard error. There is one figure for each sample under consideration: the whole sample (Panel a), students located around the admission thresholds of schools with above-median selectivity level (Panel b), and students located around the admission thresholds of schools with below-median selectivity level (Panel c). The three figures depict a significant increase in enrollment probability at the cutoffs. More precisely, the figures show that the enrollment probability of students is close to $2 \%$ below admission cutoffs, and increases by about eight percentage points for students scoring just above the cutoffs. ${ }^{17}$ This indicates that a significant share of students wants to attend a more selective school when offered this opportunity, and student willingness to attend more selective schools is somewhat higher for schools with higher selectivity levels. ${ }^{18}$ The estimates

\footnotetext{
${ }^{17}$ Note that one reason why the enrollment probability is not zero below the cutoff is that students with special needs (e.g., physical disabilities) may be accepted with a lower GPA to the geographically closest school.

${ }^{18}$ Recall that we do not know individual student preferences, hence many students could have preferences for other programs or school locations, explaining why enrollment is not increasing even more at the threshold.
} 
for $\alpha$ in model (2) in Column (1) in Table 1 confirm these results.

\subsection{Educational Outcomes}

Figure 2 and Figure 3 present the estimated effects of eligibility for enrollment in a more selective school on the subsequent education of students. We focus on two outcomes: high school graduation in the general track and enrollment in general higher education, either on time or after a gap year. Figure 2 shows a discontinuity of 2.4 percentage points at the cutoff on the likelihood of high school graduation, driven entirely by the most selective high schools (Panel b). Figure 3 exhibits no average impact on enrollment in higher education (Panel a). However, there is an increase of 2.9 percentage points for the most selective high schools (Panel b). Columns (2) and (3) in Table 1 confirm these results. Note that the main findings remain significant after accounting for multiple hypothesis testing using the procedure described in Romano and Wolf (2005). ${ }^{19}$

Our finding that eligibility for enrollment in a more selective school has positive effects on student educational outcomes differs from previous studies showing that elite school attendance in the US does not affect educational outcomes (see e.g., Abdulkadiroğlu et al., 2017, 2014; Dobbie and Fryer Jr, 2014)). However, it is in line with Pop-Eleches and Urquiola (2013) and Jackson (2013) who also consider nonelite settings and document the positive effects of attending more selective schools. ${ }^{20}$ Hence, our focus on nonelite high schools—implying that the marginal students differ by context—may be an explanation for the differences in effects compared with the US. Other features of the education system, such as the centralized admission system to higher education in Norway, may also play a role in our findings. In particular, student ranks within their class or school are not of direct importance for access to higher education because only their rank in the national high school GPA distribution is crucial for the centralized admission system. This setting is different from the setting in the US or France where rank in a class or school is a central factor in college applications (Dobbie and Fryer Jr, 2014; Landaud et al., 2018).

Columns (1) and (2) in Table A3 in the Appendix present the IV estimates, where we rescale the intention-to-treat estimates by the probability of enrollment in a selective high school upon gaining eligibility for enrolment. Panel A shows that enrollment in a more selective high school increases the probability of

\footnotetext{
${ }^{19}$ The effects on educational outcomes are greater for boys and for the children of less-educated parents, although the differences are not significant (see Table A9).

${ }^{20}$ Even for the sample of above-median selectivity, we cover a large part of the GPA distribution. The more selective school admission cutoffs are located between the $39^{\text {th }}$ and the $97^{\text {th }}$ percentiles of the test score distribution after middle school in the areas of interest and on average located around the $63^{\text {rd }}$ percentile.
} 
high school graduation and enrollment in higher education by 28 and 19 percentage points, respectively. While these estimates are large, the results are quite imprecise, and we cannot rule out quite modest effects. In most cases though, the IV estimates are statistically different from zero for the same outcomes as the reduced form effects. As discussed in subsection 3.3, we should interpret these results cautiously for several reasons. First, while the effects sizes are large in magnitude, the confidence intervals are also large and so we cannot rule out quite modest effects. Second, the compliers may differ from the average student around the discontinuity. Lastly, there could be violations of the exclusion restriction if eligibility operates through mechanisms other than enrollment. However, the fact that we find that many of the impacts evolve after high school suggests that this is likely not the main driver.

\subsection{Health Outcomes}

Next, we analyze the impacts of eligibility for enrollment in a more selective school on student health during and following high school. We first focus on the probability and number of visits to GPs or ERs. We then split the visits into two types: visits during which patients are diagnosed or treated for a mental health issue (i.e., ICPC-02 codes beginning with a "P" as described in Appendix B) and visits for other health assessments or treatments. Figure 4 depicts no discontinuities around the eligibility cutoffs in the probability of consulting with GPs or ERs (for any type of visit) during the six years after middle school graduation. However, Figure 5 shows a reduction of 1.7 percentage points in the likelihood of being diagnosed or treated for a mental health problem during GP or ER visits (Panel a). Individuals gaining access to high schools with above-median selectivity levels (Panel b) drive this fall. The estimates in Columns (4)-(7) in Table 1 present the corresponding point estimates for $\alpha$ in model (2). As shown, the estimated effect on mental health is driven by female students (see Column (5) in Table A9) and is stronger post high school (see Table A5). ${ }^{21}$

In Table 2, we examine the use of primary health care services in detail. In particular, we use the ICPC-2 codes to classify the different types of mental health problems, and create four categories: anxiety or depression symptoms and diseases, substance use, hyperkinetic disorders, and other psychological symptoms or disorders (see Table A4 for the classification of mental health conditions). ${ }^{22}$ As shown, the reduction in

\footnotetext{
${ }^{21}$ Columns (3) and (4) in Table A3 in the Appendix present the corresponding IV estimates, carrying with them the same cautiousness in interpretation as discussed for educational outcomes. Enrollment in a more selective high school instrumented by eligibility reduces the likelihood of being diagnosed or treated by a GP or an ER for psychological symptoms and diseases by 21 percentage points.

${ }^{22}$ We bundle anxiety and depression together given the possibility of co-diagnoses and common treatments for both conditions (see, e.g., Pratt et al. (2017)). Hyperkinetic disorders include inattention, overactivity, and impulsivity. They include a variety of attention disorders such as attention deficit disorder (ADD) and attention deficit hyperactivity disorder (ADHD).
} 
visits with depression or anxiety drives the reduction in the likelihood of consultations with mental health diagnoses or treatments. Note that this finding remains significant after adjusting the inference for multiple hypothesis testing.

\subsection{Robustness Checks}

To assess the robustness of our results, we check whether our main findings are sensitive to the choice of control variables, to different functional forms, to alternative bandwidths, and to focusing separately on the two cities we consider.

In our main specification, model (2), we control for several predetermined individual characteristics. In Table A6 we check that our main findings are robust to excluding these control variables, or to selecting a smaller set of control variables. Table A6 presents estimates for five outcomes: high school enrollment, high school graduation, enrollment in higher education, the probability of visits to GP/ER, and the probability of mental health diagnosis or treatment. For each outcome in Table A6, the first column does not include controls for the predetermined individual characteristics. In the second column, we select relevant control variables using the double lasso procedure suggested in Belloni et al. (2013). The point estimates remain nearly unchanged relative to our baseline results.

In addition, the estimates reported in Table A7 show that our main findings are robust to different functional forms for the running variable. Our preferred model controls for a linear spline function of the running variable with triangular weights. Table A7 presents the results with alternative functional forms for each of the five main outcomes. For each of the outcomes in Table A7, we allow for cutoff-specific trends when estimating model (2) in the first column. In the second column, we follow Lee and Lemieux (2010) who propose goodness-of-fit tests as an ancillary means to select an optimal polynomial function. In the third column, we employ nonparametric estimations using local linear regressions. The results are again similar to our baseline estimates.

In Figure A4, we report the point estimates and confidence intervals for our main outcomes for a wide range of bandwidths. The estimates show that our baseline estimates are highly robust to the choice of bandwidths in the neighborhood of the optimal bandwidth (i.e., the bandwidth that minimizes the mean square error).

Last, we turn our attention to see if a particular city is driving our main results. Table A8 presents estimates for $\alpha$ in equation 2 separately for each city (Bergen and Oslo). The estimates for $\alpha$ are similar 
for both cities, suggesting that the main findings are not driven by one city alone. This provides suggestive evidence regarding the external validity of our results across cities.

There are different explanations for our estimated impacts on mental health. More selective schools could have an incapacitation effect if, for example, students have to study longer hours in more selective schools and do not have time to visit health services. This does not appear as a likely mechanism because we do not find any impact on the extensive or intensive margin of visits to GP/ER (Columns (4) and (5) of Table 1). Alternatively, our effects could reflect differences across schools in the availability or quality of school nurses. ${ }^{23}$ To shed light on this potential mechanism, we evaluate year by year how GP or ER consultations with a psychological diagnosis or treatment vary across our sample. If school nurses were substitutes for psychological consultations during high school years, we would expect a sharp rise in the number of consultations with a psychological diagnosis or treatment after high school graduation (i.e., between year three and year four post-middle school graduation). Figure A3 in the Appendix reports the prevalence of mental health diagnoses or treatments upon GP/ER visits in our sample for each year after middle school graduation. The figure depicts a stable increase in the prevalence of primary health services with mental health diagnoses or treatments, which provides suggestive evidence that school nurses do not seem to act as substitutes for GP/ER visits. Finally, in our setting, gaining access to a more selective school also implies gaining access to a preferred school. As discussed earlier, our estimated effects on mental health appear mostly after high school (see Table A5), providing suggestive evidence that our effects do not reflect the mere short-term effect of enrolling (or failing to enroll) in a preferred school. Overall, our results do not seem driven by incapacitation effects, differences in the supply of health services, nor do they seem to link to a short-term feeling of success or failure. Rather, our results suggest that a more selective schooling environment is protective of (female) mental health. It is still possible that students perceive a more selective high school environment as more stressful, but our results suggest that the positive aspects of a more selective environment outweigh any potential increase in school pressure.

In section 5, we turn to studying whether peer and teacher characteristics or other school features vary discontinuously at the thresholds and whether these changes in school characteristics help to explain the effects on student mental health and longer-term educational outcomes.

\footnotetext{
${ }^{23}$ As discussed in Section 2.3, school nurses are employed by municipalities not by schools.
} 


\section{Suggestive Mechanisms}

Although all public Norwegian high schools follow a similar national curriculum, high schools vary along several dimensions. Because high school assignment is based on middle school GPA, student average ability varies significantly from one high school to another. Further, as a student's middle school GPA is correlated with their gender and family background, the proportion of female students and student parental backgrounds may also vary significantly across high schools. In addition, schools are independent in their hiring decisions resulting in a heterogeneous distribution of teacher characteristics across schools. Moreover, the allocation of financial resources to schools depends on the number of students, so that financial resources also vary by school size. To provide insights into what features of the schooling environment may influence student health and education outcomes, we also investigate changes in school characteristics at the thresholds. In a second step, we implement a heterogeneity analysis where we estimate our regression discontinuity model for each admission threshold and each school feature separately. This helps us to consider whether changes in longer-term educational choices and health outcomes are larger when students gain eligibility to schools where peer characteristics, teacher characteristics, or school resources change by a larger margin at the admission threshold.

First, Table 3 documents changes in peer characteristics at the threshold. Panel A of Table 3 shows that eligibility for enrollment in a more selective school improves the ability level of peers, increasing peer average middle school GPA by $4.4 \%$ of a standard deviation. ${ }^{24}$ Just above the threshold, peers also have more educated parents with higher income levels. In contrast, we do not identify differences in the gender composition of peers on average (Panel A). The estimated impacts on peer ability are similar for high schools in the top and bottom halves of the selectivity distribution (Panels B and C). However, eligibility to enroll in a more selective school increases the share of female peers for the top half of the selectivity distribution but does not change peer parental background. On the contrary, there is no effect on the share of female peers, but a significant impact on peers' parental income and education for schools with lower selectivity levels.

Next, we explore how eligibility for enrollment impacts the high school educational program and school and teacher characteristics (see Table 4). The estimates in Columns (1) and (2) show that eligibility to enroll in a more selective high school increases the likelihood of enrolling in the general track, and correspondingly decreases the probability of enrolling in the vocational track. There are no impacts on high school programs

\footnotetext{
${ }^{24}$ For each student, we computed the average standardized middle school GPA among students enrolled in the same track and high school in August following middle school completion.
} 
around the cutoffs of highly selective high schools (Panel B); instead, schools in the bottom half of the selectivity distribution (Panel C) appear to drive this program substitution.

Then, we study school financial resources and the number of teachers and staff members per student. As discussed, the central allocation of financial resources is to schools based on the number of students. Hence, we proxy financial resources by the number of students enrolled in the same program-cohort. The estimates in Column (3) show that eligibility to enroll in a more selective high school is associated with 4.76 extra students in each student's own program at the cutoff (i.e., about $7 \%$ of the control mean). This appears driven by high schools in the bottom half of the selectivity distribution. Eligibility to enroll in a more selective high school also decreases the number of students per teacher but does not change the number of students per nonteaching staff (Columns (4) and (5)).

Lastly, we consider variations in teacher characteristics. In particular, we study whether eligibility to enroll in a more selective school changes the proportion of teachers with a master degree, the average age of high school teachers, and the proportion of female teachers. Panel A shows no significant discontinuities in teacher characteristics, expect for the proportion of female teachers.

In sum, enrollment in a more selective high school not only directly affects the characteristics of the peers with whom students interact but also the types of programs in which students enroll, the characteristics of their teachers and their number, and the financial resources of their school. The impacts on peers, teachers, and resources vary across the selectivity distribution and motivate the next section where we use these variations to explore the most likely mechanism driving our estimates.

\subsection{Heterogeneity Analysis by Changes in School Inputs at the Thresholds}

\subsubsection{Empirical Approach}

To further our understanding of selective school effects on education and health, we develop a heterogeneity analysis, which makes use of the fact that we have 84 different admission cutoffs with variations in how school characteristics change around these cutoffs. In our setting, for each admission threshold, the magnitude of the estimated eligibility effects on school inputs depends on two parameters: (1) the characteristics of the high school corresponding to the admission threshold under consideration and (2) the characteristics of high schools with lower selectivity levels. In this section, we analyze whether we obtain larger estimated effects on health and education around thresholds with larger changes in peer characteristics, 
teacher characteristics, or other school features.

We restrict the analysis to two outcomes of interest: student enrollment in higher education and the probability of diagnosis or treatment of students by GPs or ERs for psychological conditions. We consider 11 different school inputs: the average middle school GPA of peers, the proportion of female students among high school peers, the parental education of peers, peers' parental income, the proportion of teachers with a master degree, the average age of teachers, the proportion of female teachers, the number of students per teacher, school size, the number of students per nonteaching staff, and student probability of enrolling in the general track. For each admission threshold $z$ and each school input $m$, we estimate our standard RD model described in the previous section:

$$
Y_{m, z, i}=\delta_{m, z}+\alpha_{m, z} \mathbb{1}\left\{f_{i}-f_{z} \geq 0\right\}+\eta_{m, z}\left(f_{z}-f_{i}\right)+\lambda_{m, z}\left(f_{i}-f_{z}\right) \times \mathbb{1}\left\{f_{i}-f_{z} \geq 0\right\}+X_{i} \gamma+u_{m, z, i}
$$

The only difference relative to model (2) is that we estimate model (3) for each admission threshold separately, rather than pooling all admission thresholds with cutoffs by year fixed effects. For each school input and each admission threshold, we obtain the estimated parameters $\widehat{\alpha_{m, z}}$, which indicate the magnitude of the variation in the school input $m$ around the admission threshold $z$. For each school input separately, we then divide the sample depending on whether the estimated effect on the input under consideration is above or below the median estimated effect, $\widetilde{\alpha_{m, z}}$.

For each outcome and school input, we then estimate our basic RD model separately on subsamples characterized by the magnitude of the change in the school input under consideration at the thresholds. We use this heterogeneity analysis to respond to the following question: do larger changes in peer characteristics or teacher characteristics or in other school features coincide with greater estimated effects on student education and mental health?

\subsection{Findings}

Figure 6 provides the results of our heterogeneity analysis. First, Panel a in Figure 6 documents that there are significant differences in how each school input varies at the thresholds. Along all the dimensions we consider, the average change at the threshold in the input under consideration is significantly different for schools with a below- or above-median change. For example, for one group of schools, eligibility for 
enrollment in a more selective school implies an increase in the share of female peers, while it implies a decrease in the share of female peers in the second group of schools. Similarly, for one group of schools, eligibility for enrollment in a more selective school implies an increase in the ratio of students per teacher, but a decrease in this ratio for the second group of schools.

Panel $b$ of Figure 6 reports the RD results on enrollment in higher education using the same subsamples as in Panel a. This figure documents two significant differences: larger changes in the student-teacher ratio and the age of teachers coincide with larger estimated effects on enrollment in higher education. Panel c of Figure 6 reports the results for the probability of diagnosis or treatment by a GP for psychological symptoms or diseases. We identify significant differences in the estimated effects depending on the changes in the proportion of female teachers. By contrast, we find no empirical evidence that larger changes in peer ability or gender are important drivers of the results for education or health outcomes. Overall, our heterogeneity analysis suggests that changes in teacher characteristics are probably important to explain the observed positive impacts of attending a more selective high school.

Note that this analysis is only descriptive and that we should not interpret the findings as causal effects. The estimates are also not fully robust to the adjustments for multiple hypothesis testing. Moreover, the analysis does not exclude alternative mechanisms such as changes in student ambitions or confidence in the future.

\section{Conclusion}

This paper provides new insights into the relationship between the selectivity of the schooling environment and student educational outcomes and mental health. To identify causal effects, we build on the features of the high school assignment system in the two largest Norwegian cities, where the assignment of middle school students to high school is through a centralized process that gives priority to students with the best average middle school grades. This assignment system enables a regression discontinuity analysis, where we compare the education and health outcomes of students that are similar at the end of middle school but are eligible to enroll in more or less selective high schools. The direction of the effect on health and education outcomes is theoretically ambiguous. On the one hand, a selective school environment might be a stressful experience for marginal students and increase their (mental) health problems. On the other hand, a more selective school with better peers and different teachers might be an inspiring experience that opens up new 
perspectives and improves student (mental) health in both the short and long term.

Our results show that eligibility for enrollment in a more selective school significantly improves school outcomes, increasing the likelihood of both high school completion and enrollment in higher education. In addition, we document that the eligibility to enroll in a more selective school does not affect the overall use of primary care services up to six years after high school completion, but does decrease a student's likelihood of diagnosis or treatment by a GP for mental health issues. These estimated effects on education and mental health appear driven by access to schools in the top half of the selectivity distribution, whereas female students drive the health effects.

Our heterogeneity analysis exploiting the 84 different admission cutoffs reveals that larger changes in the student-teacher ratio and age of teachers coincides with larger estimated effects on enrollment in higher education, and that larger changes in the share of female teachers coincide with larger estimated effects on student mental health. Overall, our heterogeneity analysis suggests that changes in teacher characteristicsand not necessarily peer characteristics — could be important for explaining the effects of a more selective school environment for a student's subsequent education and health.

An important open question for future research concerns the relationship between the estimated effects on health and educational outcomes. Do students graduate more from high school and enroll more in higher education because they are in better health (especially better mental health), or are they in better health because they are boosted by better educational prospects? Previous literature analyzing the effect of increases in compulsory education or changes in school tracking suggests that there are positive effects of expanding compulsory schooling on women's mental health and particularly self-reported depressive symptoms (Böckerman et al., 2019; Crespo et al., 2014; Dursun and Cesur, 2016). A question remains whether better educational prospects by the end of high school have similar positive effects on mental health. Alternatively, it could also be the case that similar improvements in school inputs drive both health and longer-term educational outcomes, even if they do not affect each other. For example, Elsner and Isphording (2017) argue that the ordinal ability rank of students in their cohort, which is negatively impacted when students gain eligibility to a more selective school, is an important determinant of engaging in risky behaviors that can impact both educational and health outcomes.

Besides complementing the existing literature on the effects of school selectivity on educational outcomes, we provide new knowledge on the relationship between school selectivity and mental health, and demonstrate that access to more selective schools decreases the risk of mental health problems. While a selective school 
environment might still be a stressful experience for marginal students, our results suggest that the positive effects of enrolling in a more selective school outweigh this extra pressure over the long term. 


\section{References}

Abdulkadiroğlu, Atila, Joshua D. Angrist, Yusuke Narita and Parag A. Pathak. 2017. "Research Design Meets Market Design: Using Centralized Assignment for Impact Evaluation.” Econometrica, 85 1373-1432, URL: https://ideas.repec.org/a/wly/emetrp/v85y2017ip1373-1432 .html.

Abdulkadiroğlu, Atila, Joshua Angrist and Parag Pathak. 2014. "The Elite Illusion: Achievement Effects at Boston and New York Exam Schools.” Econometrica, 82(1): 137-196.

Abrahamsen, Signe A., Rita Ginja and Julie Riise. 2019. "VSchool Health Programs: Education, Health, and Welfare Dependency of Young Adults.” MIMEO.

Bakken, Anders. 2018. Ungdata 2018. Nasjonale resultater.: Norsk institutt for forskning om oppvekst, velferd og aldring (NOVA).

Belloni, Alexandre, Victor Chernozhukov and Christian Hansen. 2013. "Inference on Treatment Effects after Selection among High-Dimensional Controls $\uparrow . "$ The Review of Economic Studies, 81(2): 608-650, DOI: http://dx.doi.org/10.1093/restud/rdt044.

Böckerman, Petri, Mika Haapanen, Christopher Jepsen and Alexandra Roulet. 2019. "School Tracking and Mental Health.” IZA Discussion Papers.

Calonico, Sebastian, Matias D. Cattaneo and Rocio Titiunik. 2014. "Robust Nonparametric Confidence Intervals for Regression - Discontinuity Designs.” Econometrica, 82(6): 2295-2326.

Card, David, Alexandre Mas and Jesse Rothstein. 2008. "Tipping and the Dynamics of Segregation*." The Quarterly Journal of Economics, 123(1): 177-218.

Carneiro, Pedro, Emanuela Galasso and Rita Ginja. 2019. “Tackling Social Exclusion: Evidence from Chile.” The Economic Journal, 129(617): 172-208.

Clark, Damon and Emilia Del Bono. 2016. "The Long-Run Effects of Attending an Elite School: Evidence from the United Kingdom." American Economic Journal: Applied Economics, 8(1): 150-76, DOI: http://dx.doi.org/10.1257/app.20130505.

Clark, Damon and Heather Royer. 2013. "The Effect of Education on Adult Mortality and Health: Evidence from Britain.” American Economic Review, 103(6): 2087-2120. 
Crespo, Laura, Borja López-Noval and Pedro Mira. 2014. "Compulsory schooling, education, depression and memory: New evidence from SHARELIFE.” Economics of Education Review, 4336 - 46.

Cullen, Julie Berry, Brian A Jacob and Steven Levitt. 2006. "The Effect of School Choice on Participants: Evidence from Randomized Lotteries.” Econometrica, 74(5): 1191-1230.

Currie, Janet, Mark Stabile, Phongsack Manivong and Leslie L. Roos. 2010. "Child Health and Young Adult Outcomes." The Journal of Human Resources, 45(3): 517-548, URL: http://www . jstor . org/ stable/25703468.

Dobbie, Will and Roland G Fryer Jr. 2014. "The Impact of Attending a School with High-Achieving Peers: Evidence from the New York City Exam Schools." American Economic Journal: Applied Economics, 6(3): $58-75$.

Dursun, Bahadır and Resul Cesur. 2016. "Transforming lives: the impact of compulsory schooling on hope and happiness." Journal of Population Economics, 29(3): 911-956.

Elsner, Benjamin and Ingo E. Isphording. 2017. “Rank, Sex, Drugs and Crime.” Journal of Human Resources.

Eriksen, Ingunn Marie, Mira Aaboen Sletten, Anders Bakken and Tilman von Soest. 2017. Stress og press blant ungdom. Erfaringer, årsaker og utbredelse av psykiske helseplager.: Oslo Metropolitan UniversityOsloMet: NOVA.

Fack, Gabrielle, Julien Grenet and Yinghua He. 2019. "Beyond Truth-Telling: Preference Estimation with Centralized School Choice and College Admissions." American Economic Review, 109(4): 1486-1529.

Fletcher, Jason M. and David E. Frisvold. 2011. "College selectivity and young adult health behaviors." Economics of Education Review, 30(5): 826 - 837.

Fletcher, Jason M. and David E. Frisvold. 2014. "The long run health returns to college quality." Review of Economics of the Household, 12(2): 295-325.

Frisvold, David and Ezra Golberstein. 2011. "School quality and the education-health relationship: Evidence from Blacks in segregated schools." Journal of Health Economics, 30(6): 1232 - 1245. 
Goodman, A., R. Joyce and J. P. Smith. 2011. "The long shadow cast by childhood physical and mental problems on adult life." Proceedings of the National Academy of Sciences of the United States of America, 108(15): 6032-6037.

Hahn, Jinyong, Petra Todd and Wilbert Van der Klaauw. 2001. "Identification and Estimation of Treatment Effects with a Regression-Discontinuity Design.” Econometrica, 69(1): 201-209.

Hansen, Bruce E. 2000. “Sample Splitting and Threshold Estimation.” Econometrica, 68(3): 575-603.

Helse- og omsorgsdepartementet. 2003. "Forskrift om helsestasjons- og skolehelsetjenesten." Online; accessed 1 May 2018 https://lovdata.no/dokument/LTI/forskrift/2003-04-03-450.

Helsetilsyn, Statens. 1998. "Veileder for helsestasjons- og skolehelsetjenesten.” Veileder IK-2617.

HHS. 2017. "Adolescent Health.” Online; accessed 10 June 2020 https://opa.hhs.gov/adolescent-health?adolescent-development/mental-health/ mental-health-disorders/index.html.

Hoekstra, Mark. 2009. "The Effect of Attending the Flagship State University on Earnings: A DiscontinuityBased Approach." The Review of Economics and Statistics, 91(4): 717-724.

Jackson, C Kirabo. 2013. "Can Higher-achieving Peers Explain the Benefits to Attending Selective Schools? Evidence from Trinidad and Tobago.” Journal of Public Economics, 108 63-77.

Kirkeboen, Lars J., Edwin Leuven and Magne Mogstad. 2016. "Field of Study, Earnings, and SelfSelection*." The Quarterly Journal of Economics, 131(3): 1057-1111, DOI: http://dx.doi.org/ 10.1093/qje/qjw019.

Lager, A., D. Seblova, D. Falkstedt and M. Løvdén. 2016. “Cognitive and emotional outcomes after prolonged education: a quasi-experiment on 320182 Swedish boys." International Journal of Epidemiology, 46(1): $303-311$.

Landaud, Fanny, Son-Thierry Ly and Eric Maurin. 2018. "Competitive Schools and the Gender Gap in the Choice of Field of Study." Journal of Human Resources 0617-8864R. 
Lee, David S. and Thomas Lemieux. 2010. "Regression Discontinuity Designs in Economics." Journal of economic literature, 48(2): 281-355.

Lleras-Muney, Adriana. 2005. "The Relationship Between Education and Adult Mortality in the United States." The Review of Economic Studies, 72(1): 189-221.

Lundborg, Petter, Anton Nilsson and Dan-Olof Rooth. 2014. "Adolescent health and adult labor market outcomes." Journal of Health Economics, 3725 - 40, DOI: http://dx . doi .org/https ://doi .org/ $10.1016 / \mathrm{j}$. jhealeco.2014.05.003.

McCrary, Justin. 2008. "Manipulation of the Running Variable in the Regression Discontinuity Design: A Density Test." Journal of Econometrics, 142(2): 698-714.

Meghir, Costas, Mårten Palme and Emilia Simeonova. 2018. "Education and Mortality: Evidence from a Social Experiment." American Economic Journal: Applied Economics, 10(2): 234-256.

Pop-Eleches, Cristian and Miguel Urquiola. 2013. "Going to a Better School: Effects and Behavioral Responses." American Economic Review, 103(4): 1289-1324.

Porter, Jack and Ping Yu. 2015. "Regression Discontinuity Designs with Unknown Discontinuity Points: Testing and Estimation." Journal of Econometrics, 189(1): 132-147, URL: https://ideas.repec . org/a/eee/econom/v189y2015i1p132-147.html.

Pratt, Laura, Debra Brody and Qiuping Gu. 2017. "Antidepressant Use Among Persons Aged 12 and Over:United States,2011-2014.” NCHS data brief, 283 1-8, URL: https://www. cdc . gov/nchs/data/ databriefs/db283.pdf.

Romano, Joseph P. and Michael Wolf. 2005. "Stepwise Multiple Testing as Formalized Data Snooping." Econometrica, 73(4): 1237-1282.

Ungdata. 2018. "Stress, press og psykiske plager blant unge." Online; accessed 23 September 2020 https://www. ungdata.no/stress-press-og-psykiske-plager-blant-unge/.

WHO. 2019. "Adolescent mental health.” Online; accessed 23 September 2020 https://www. who.int/news-room/fact-sheets/detail/adolescent-mental-health. 
Figure 1 - Enrollment probability

(a) All

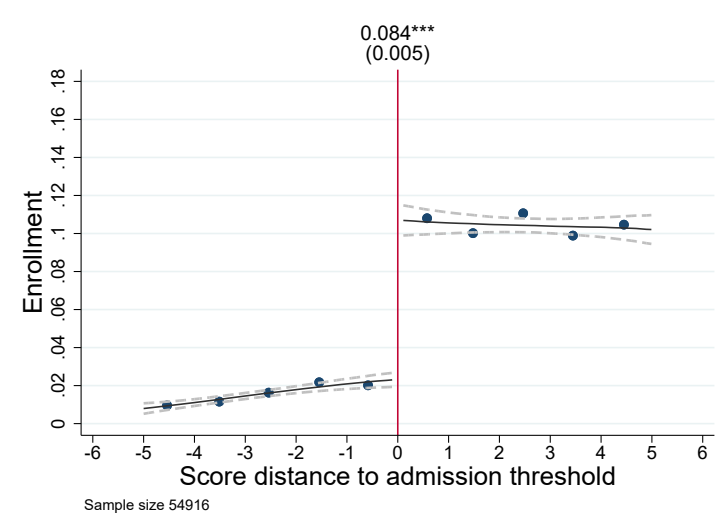

(b) Higher selectivity levels

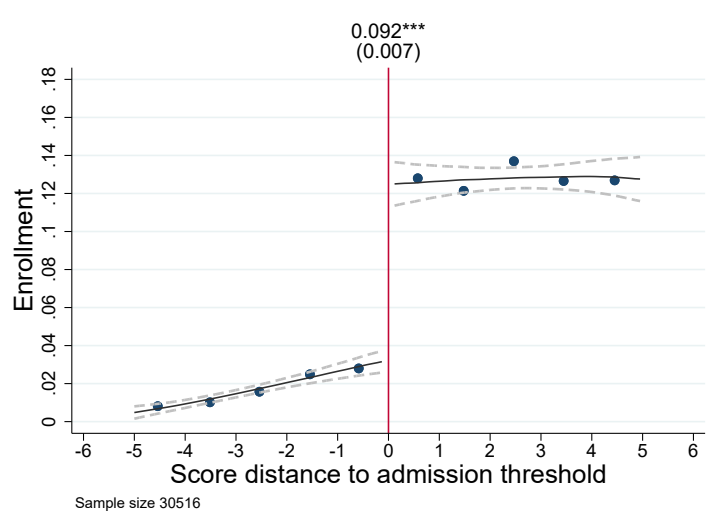

(c) Lower selectivity levels

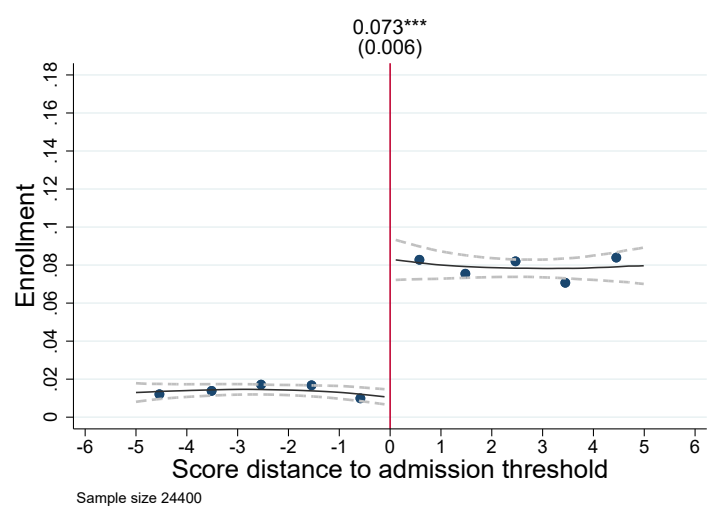

Note: These figures plot the point estimates of $\alpha$ from equation (2) using a linear trend specification and triangular weights. The standard errors for the point estimates are clustered at individual level. The dashed lines are 95 percent confidence intervals. ${ }^{* * *} \mathrm{p}<0.01, * * \mathrm{p}<0.05, * \mathrm{p}<0.1$. 
Figure 2 - High School Graduation

(a) All

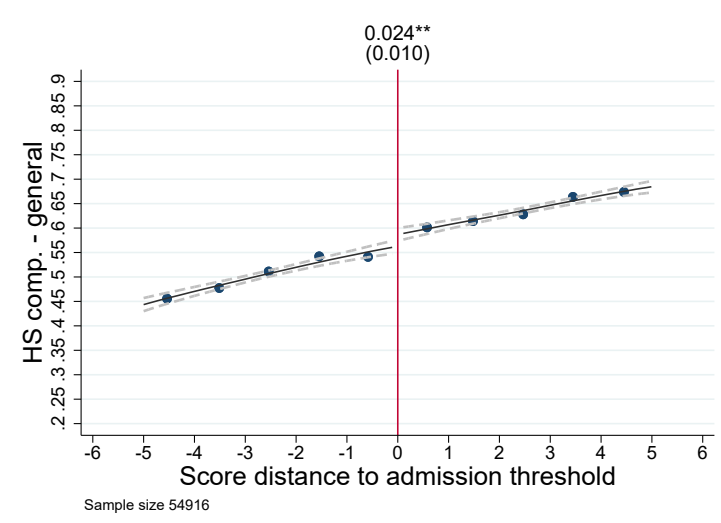

(b) Higher selectivity levels

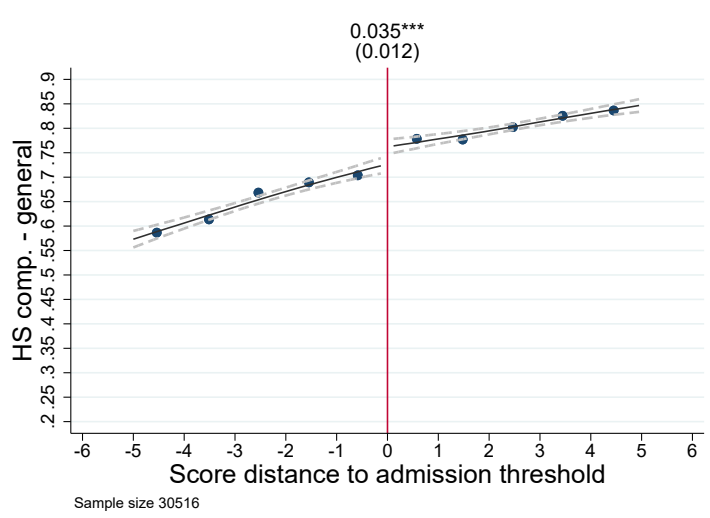

(c) Lower selectivity levels

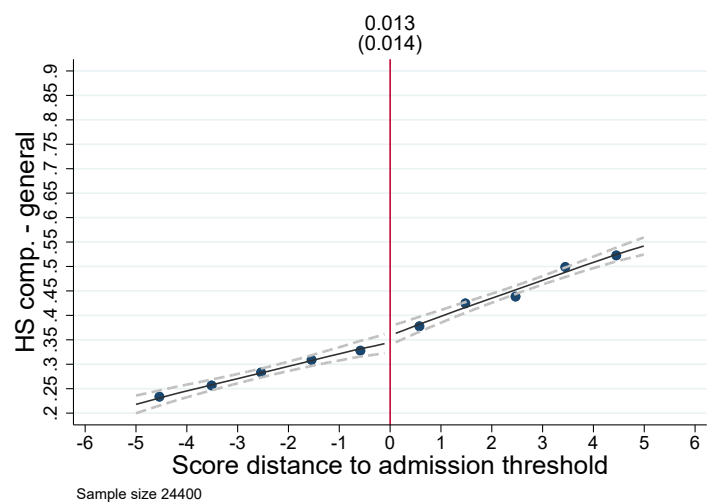

Note: These figures plot the point estimates of $\alpha$ from equation (2) using a linear trend specification and triangular weights. The standard errors for the point estimates are clustered at individual level. The dashed lines are 95 percent confidence intervals. ${ }^{* * *} \mathrm{p}<0.01, * * \mathrm{p}<0.05, * \mathrm{p}<0.1$. 
Figure 3 - Enrollment in Higher Education

(a) All

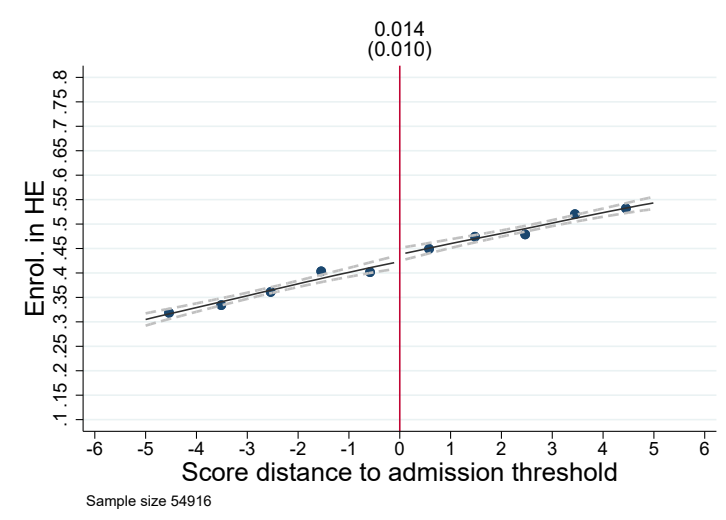

(b) Higher selectivity levels

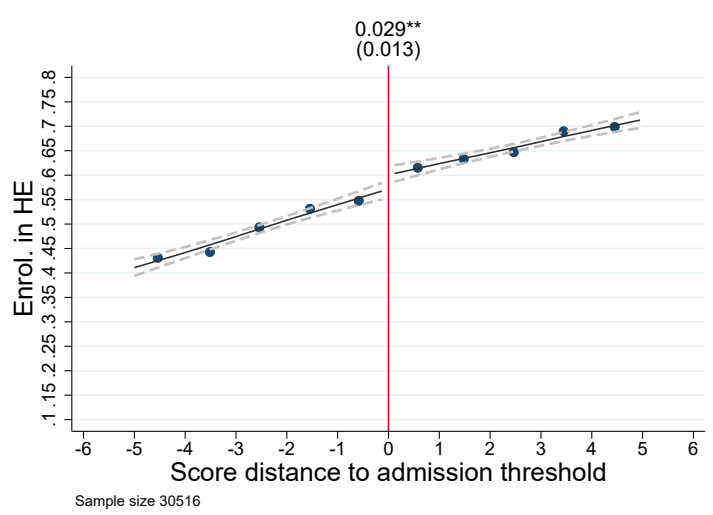

(c) Lower selectivity levels

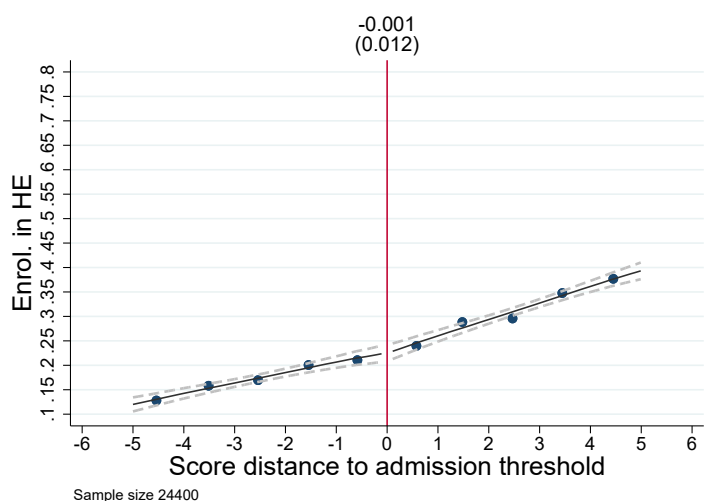

Note: These figures plot the point estimates of $\alpha$ from equation (2) using a linear trend specification and triangular weights. The standard errors for the point estimates are clustered at individual level. The dashed lines are 95 percent confidence intervals. $* * * \mathrm{p}<0.01, * * \mathrm{p}<0.05, * \mathrm{p}<0.1$. 
Figure 4 - Probability of Consulting with a GP or an ER

(a) All

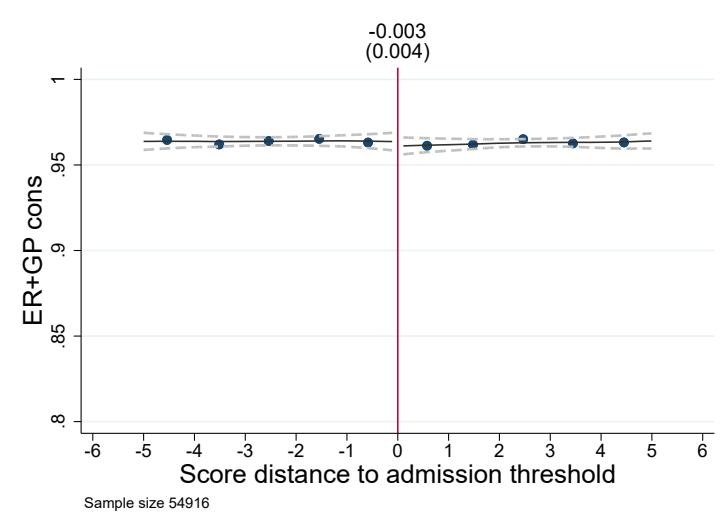

(b) Higher selectivity levels

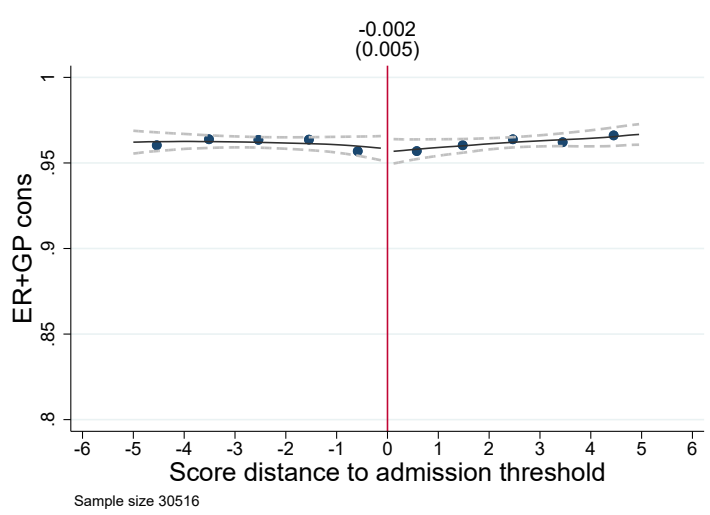

(c) Lower selectivity levels

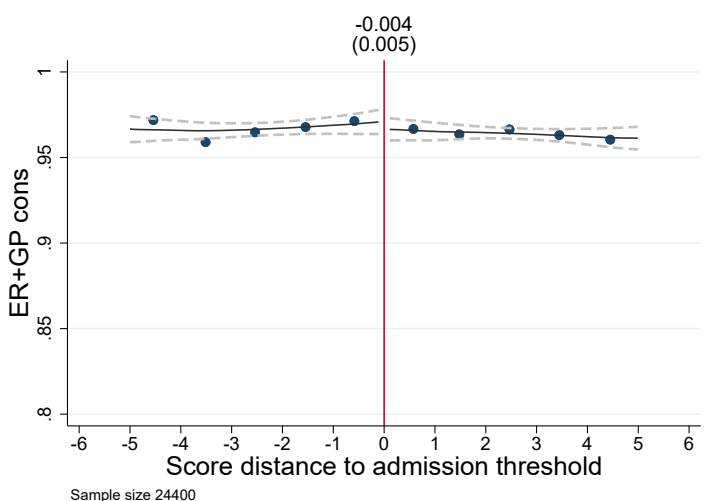

Note: These figures plot the point estimates of $\alpha$ from equation (2) using a linear trend specification and triangular weights. The standard errors for the point estimates are clustered at individual level. The dashed lines are 95 percent confidence intervals. $* * * \mathrm{p}<0.01, * * \mathrm{p}<0.05, * \mathrm{p}<0.1$. 
Figure 5 - Probability of being Diagnosed or Treated for a Mental Health Issue

(a) All

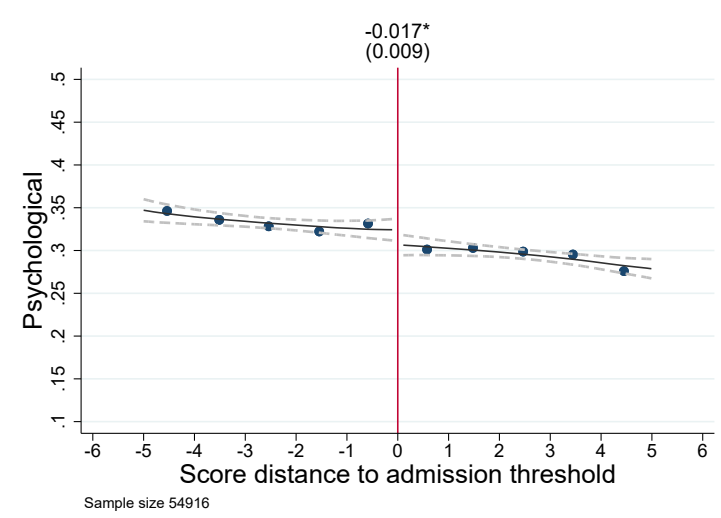

(b) Higher selectivity levels

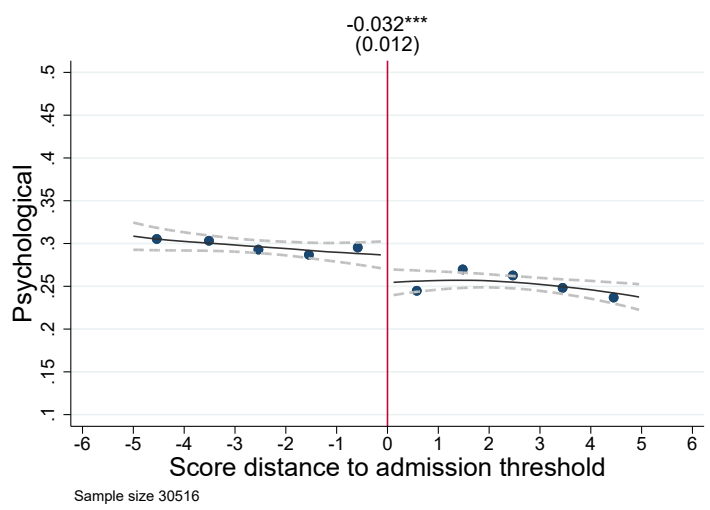

(c) Lower selectivity levels

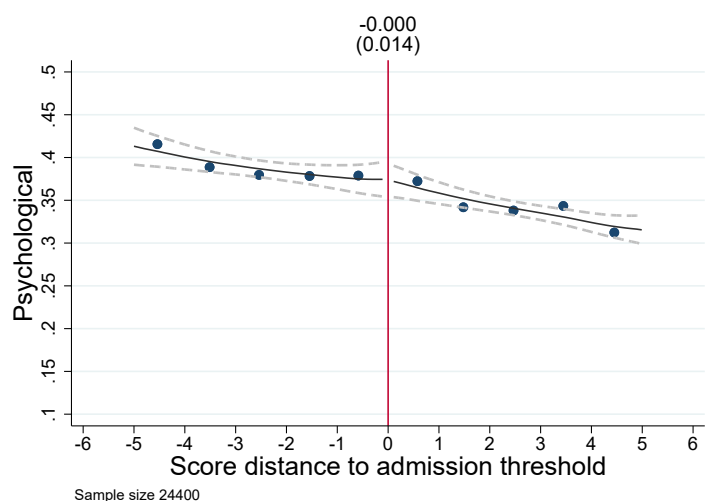

Note: These figures plot the point estimates of $\alpha$ from equation (2) using a linear trend specification and triangular weights. The standard errors for the point estimates are clustered at individual level. The dashed lines are 95 percent confidence intervals. $* * * \mathrm{p}<0.01, * * \mathrm{p}<0.05, * \mathrm{p}<0.1$. 
Figure 6 - Heterogeneity of Selective School Effects by Changes in School Characteristics

(a) Changes in School Characteristics at the Thresholds

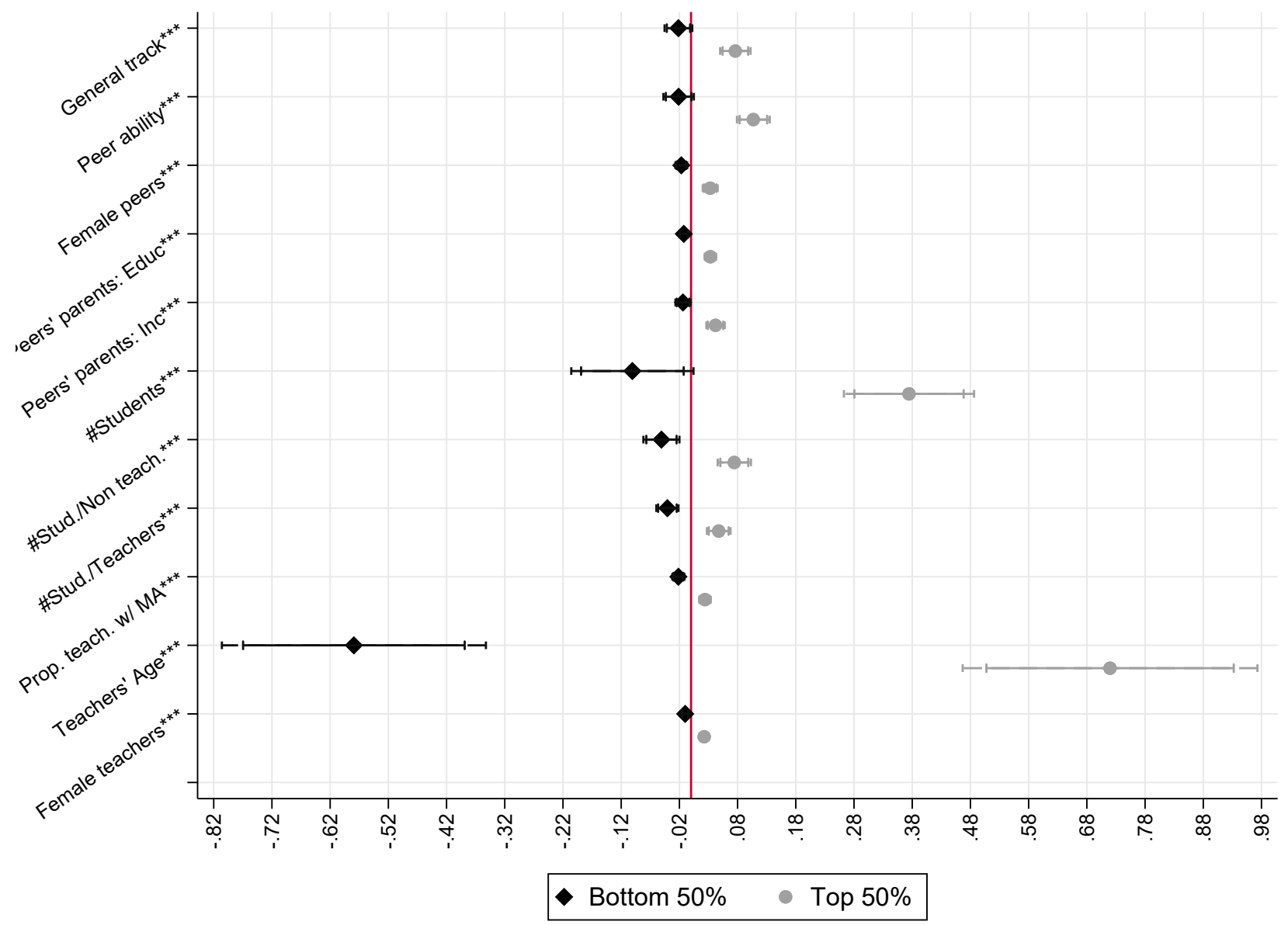

NotE: Asterisks refer to the results of tests of the null hypothesis of no difference in the changes in inputs above or below the median estimated parameter where $* * * \mathrm{p}<0.01, * * \mathrm{p}<0.05, * \mathrm{p}<0.1$. All estimates are statistically different at the 5\% level after accounting for multiple hypothesis testing using the procedure described in Romano and Wolf (2005). 
(b) Changes in School Characteristics and Enrollment in Higher Education

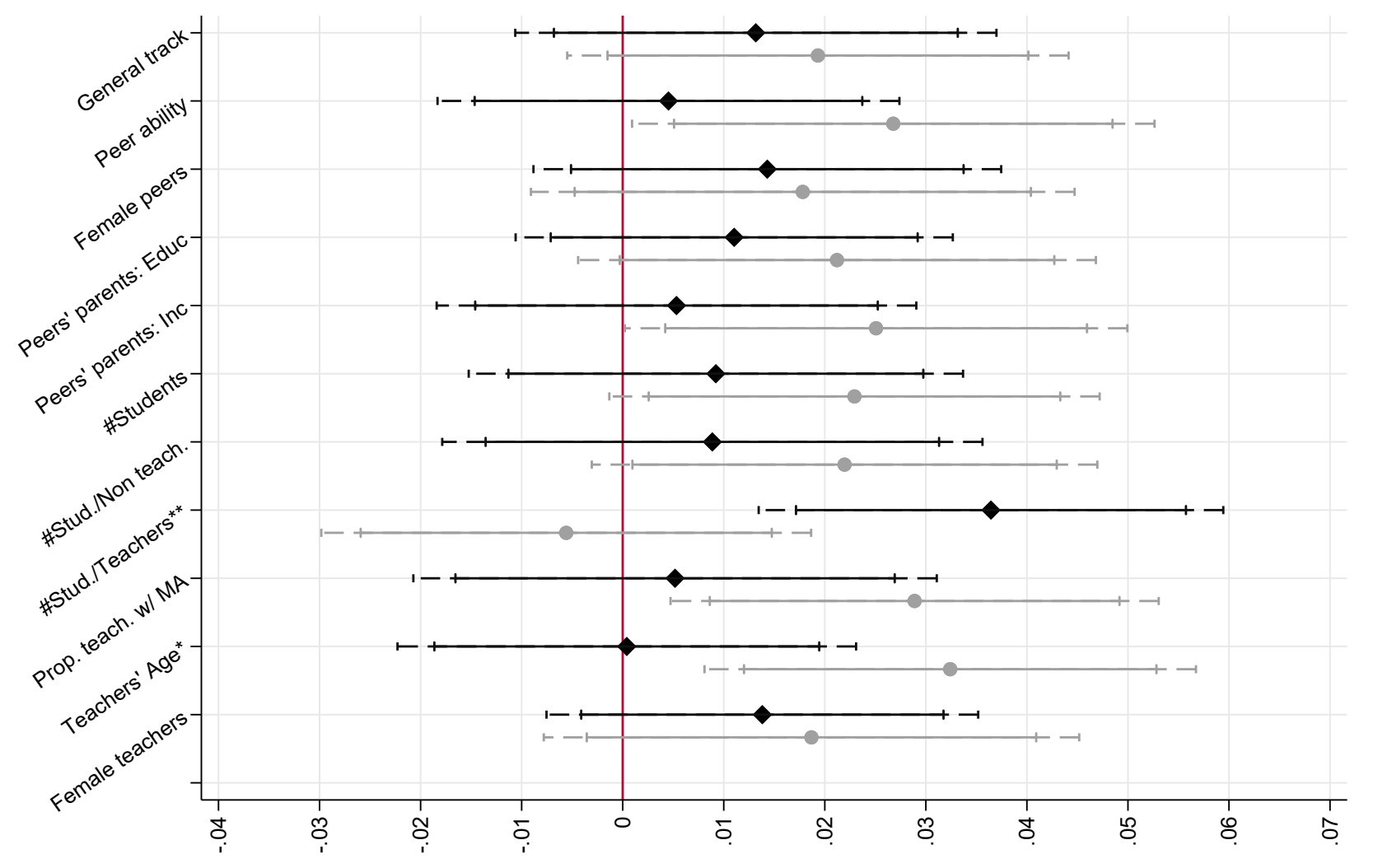

\section{- Bottom $50 \% \quad$ Top $50 \%$}

NotE: Asterisks refer to the results of tests of the null hypothesis of no difference in the changes in inputs above or below the median estimated parameter where $* * * \mathrm{p}<0.01, * * \mathrm{p}<0.05, * \mathrm{p}<0.1$. Joint tests of the estimates are no longer statistically different at the $10 \%$ (or lower) level after accounting for multiple hypothesis testing using the procedure described in Romano and Wolf (2005). 
(c) Changes in School Characteristics and Mental Health Issues

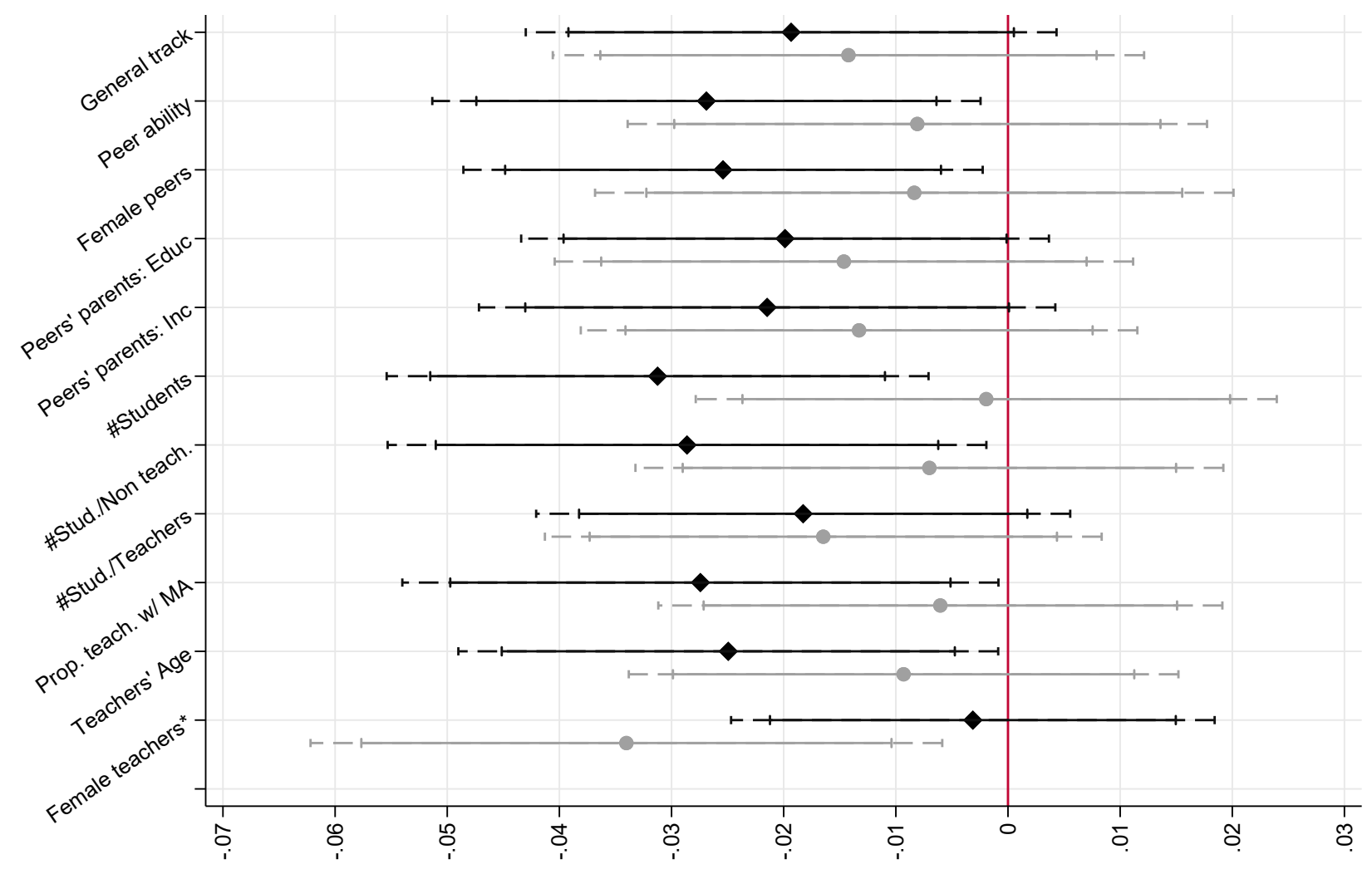

\section{- Bottom $50 \% \quad$ Top $50 \%$}

NotE: Asterisks refer to the results of tests of the null hypothesis of no difference in the changes in inputs above or below the median estimated parameter where $* * * \mathrm{p}<0.01,{ }^{* *} \mathrm{p}<0.05, * \mathrm{p}<0.1$. Joint tests of the estimates are no longer statistically different at the $10 \%$ (or lower) level after accounting for multiple hypothesis testing using the procedure described in Romano and Wolf (2005). 


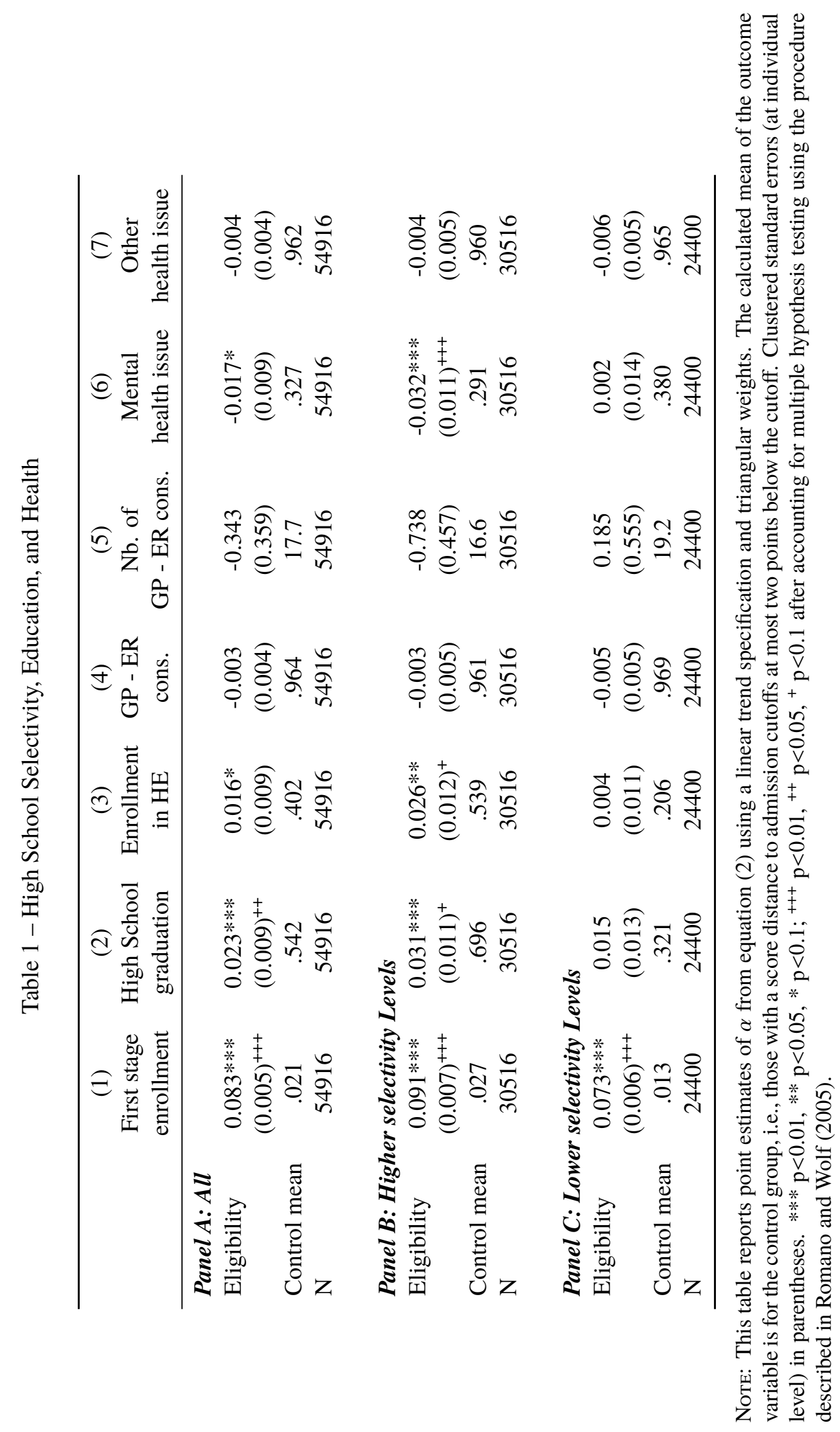


Table 2 - High School Selectivity and Mental Health Diagnoses and Treatments

\begin{tabular}{|c|c|c|c|c|}
\hline & $\begin{array}{c}(1) \\
\text { Depression/Anxiety }\end{array}$ & $\begin{array}{c}(2) \\
\text { Subs. abuse }\end{array}$ & $\begin{array}{c}(3) \\
\text { ADHD }\end{array}$ & $\begin{array}{l}\text { (4) } \\
\text { Other psy. }\end{array}$ \\
\hline \multicolumn{5}{|l|}{ Panel A: All } \\
\hline Eligibility & $\begin{array}{l}-0.015^{*} \\
(0.008)\end{array}$ & $\begin{array}{c}0.001 \\
(0.004)\end{array}$ & $\begin{array}{l}-0.004 \\
(0.003)\end{array}$ & $\begin{array}{l}-0.008 \\
(0.007)\end{array}$ \\
\hline Control mean & .233 & .0514 & .0334 & .153 \\
\hline $\mathrm{N}$ & 54916 & 54916 & 54916 & 54916 \\
\hline \multicolumn{5}{|c|}{ Panel B: Higher Selectivity Levels } \\
\hline Eligibility & $\begin{array}{l}-0.028 * * * \\
(0.010)^{+++}\end{array}$ & $\begin{array}{l}-0.001 \\
(0.005)\end{array}$ & $\begin{array}{l}-0.006 \\
(0.004)\end{array}$ & $\begin{array}{l}-0.013 \\
(0.009)\end{array}$ \\
\hline Control mean & .211 & .0384 & .024 & .134 \\
\hline $\mathrm{N}$ & 30516 & 30516 & 30516 & 30516 \\
\hline \multicolumn{5}{|c|}{ Panel C: Lower Selectivity Levels } \\
\hline Eligibility & $\begin{array}{c}0.002 \\
(0.013)\end{array}$ & $\begin{array}{c}0.004 \\
(0.008)\end{array}$ & $\begin{array}{l}-0.001 \\
(0.006)\end{array}$ & $\begin{array}{l}-0.001 \\
(0.011)\end{array}$ \\
\hline Control mean & .264 & .0701 & .0468 & .18 \\
\hline $\mathrm{N}$ & 24400 & 24400 & 24400 & 24400 \\
\hline
\end{tabular}

Note: This table reports the point estimates of $\alpha$ from equation (2) using a linear trend specification and triangular weights. The calculated mean of the outcome variable is for the control group, i.e., those with a score distance to admission cutoffs at most two points below the cutoff. Clustered standard errors (at individual level) in parentheses. *** $\mathrm{p}<0.01,{ }^{* *} \mathrm{p}<0.05, * \mathrm{p}<0.1{ }^{+++} \mathrm{p}<0.01,{ }^{++} \mathrm{p}<0.05,{ }^{+} \mathrm{p}<0.1$ after accounting for multiple hypothesis testing using the procedure described in Romano and Wolf (2005). 
Table 3 - Characteristics of High School Peers

\begin{tabular}{|c|c|c|c|c|}
\hline & \multirow{3}{*}{$\begin{array}{l}\text { (1) } \\
\text { Peers' av. MS GPA }\end{array}$} & \multirow{3}{*}{$\begin{array}{c}(2) \\
\text { Prop. of female peers }\end{array}$} & (3) & (4) \\
\hline & & & \multicolumn{2}{|c|}{$\begin{array}{l}(3) \\
\text { Parents of Peers }\end{array}$} \\
\hline & & & Av. inc. $(\log )$ & Education \\
\hline \multicolumn{5}{|l|}{ Panel A: All } \\
\hline \multirow[t]{2}{*}{ Eligibility } & $0.044 * * *$ & 0.006 & $0.016^{* * *}$ & $0.011 * * *$ \\
\hline & $(0.010)^{+++}$ & $(0.004)$ & $(0.005)^{+++}$ & $(0.003)^{+++}$ \\
\hline Control mean & .0644 & .463 & 13.5 & .481 \\
\hline $\mathrm{N}$ & 54916 & 54916 & 54916 & 54916 \\
\hline \multicolumn{5}{|c|}{ Panel B: Higher Selectivity Levels } \\
\hline \multirow[t]{2}{*}{ Eligibility } & $0.039 * * *$ & $0.012 * * *$ & 0.011 & 0.007 \\
\hline & $(0.012)^{+++}$ & $(0.004)^{+++}$ & $(0.007)$ & $(0.004)$ \\
\hline Control mean & .353 & .496 & 13.8 & .568 \\
\hline $\mathrm{N}$ & 30516 & 30516 & 30516 & 30516 \\
\hline \multicolumn{5}{|c|}{ Panel C: Lower Selectivity Levels } \\
\hline \multirow[t]{2}{*}{ Eligibility } & $0.046^{* * *}$ & 0.000 & $0.018 * * *$ & $0.015^{* * *}$ \\
\hline & $(0.015)^{+++}$ & $(0.007)$ & $(0.007)^{+++}$ & $(0.005)^{+++}$ \\
\hline Control mean & -.349 & .416 & 13.1 & .357 \\
\hline $\mathrm{N}$ & 24400 & 24400 & 24400 & 24400 \\
\hline
\end{tabular}

NotE: This table reports the point estimates of $\alpha$ from equation (2) using a linear trend specification and triangular weights. The calculated mean of the outcome variable is for the control group, i.e., those with a score distance to admission cutoffs at most two points below the cutoff. Clustered standard errors (at individual level) in parentheses. $* * * \mathrm{p}<0.01,{ }^{* *} \mathrm{p}<0.05,{ }^{*} \mathrm{p}<0.1{ }^{+++} \mathrm{p}<0.01,{ }^{++} \mathrm{p}<0.05,{ }^{+} \mathrm{p}<0.1$ after accounting for multiple hypothesis testing using the procedure described in Romano and Wolf (2005). 


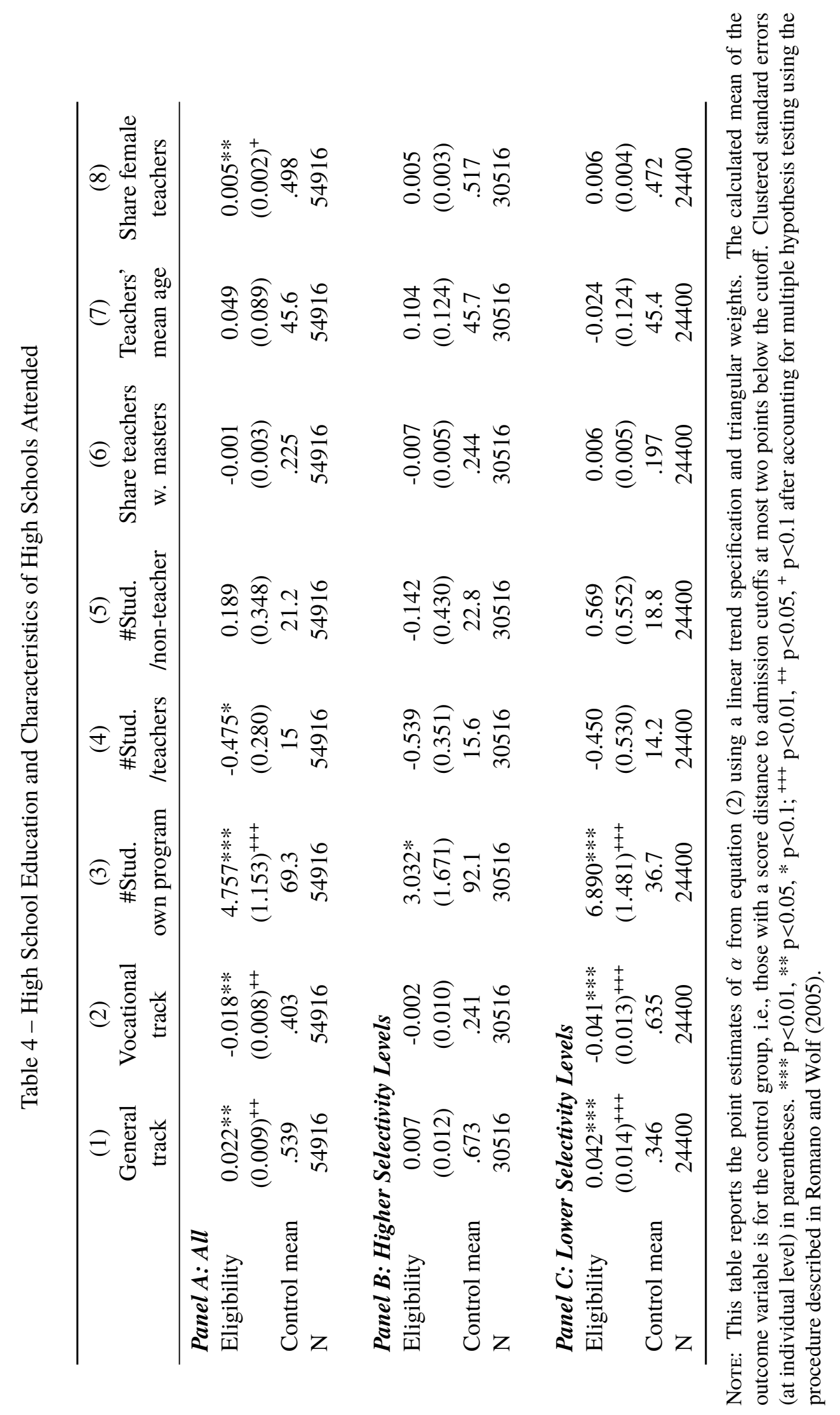


Appendix A 
Figure A1 - Density of Observations around Admission Cutoffs

(a) All

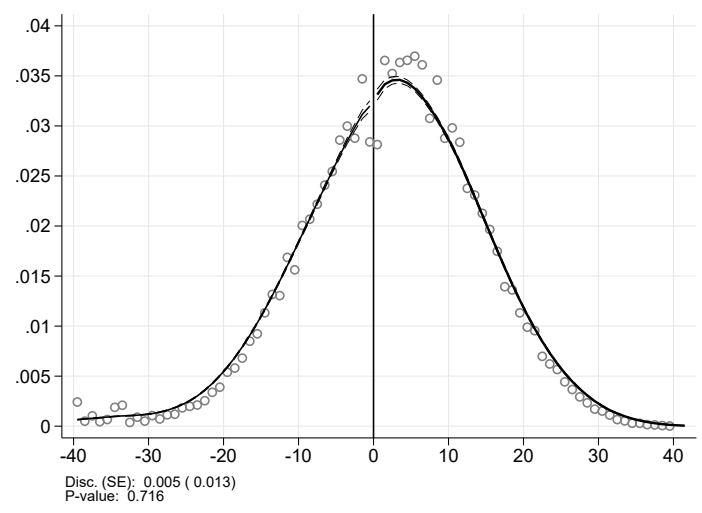

(b) Higher selectivity levels

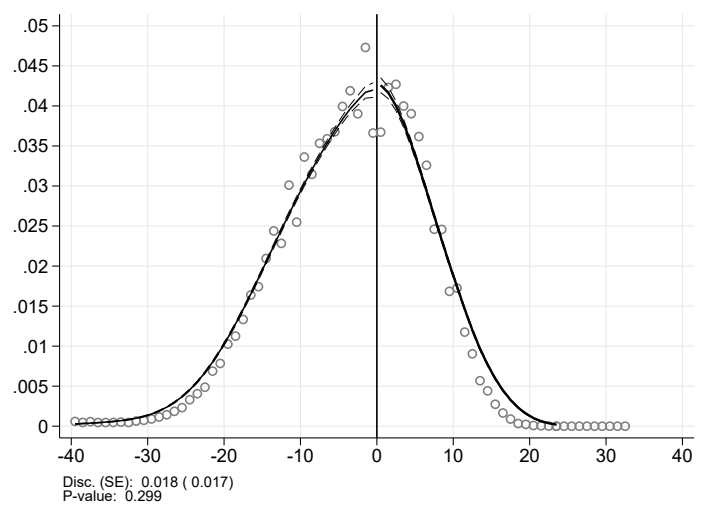

(c) Lower selectivity levels

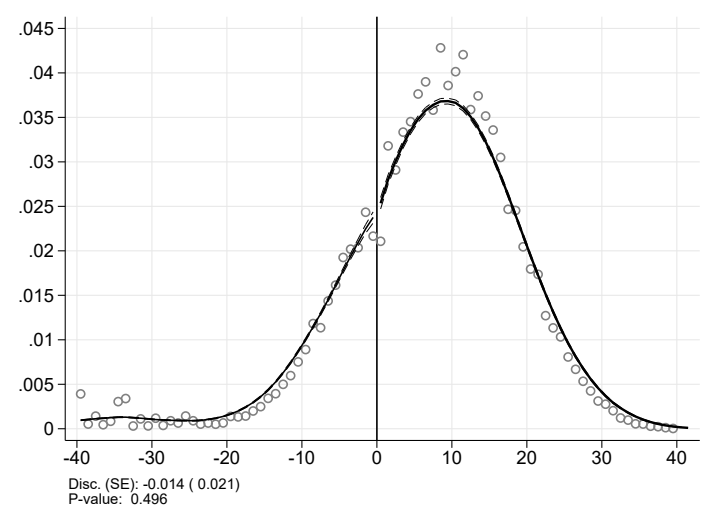

Note: These figures present nonparametric estimates of the density of observations on either side of the cutoff score following McCrary (2008). Each circle shows the average frequency of students per bin of the running variable. The solid lines represent estimated density functions, and the dashed lines are the 95 percent confidence intervals around it. The bottom right of each figure includes the estimated discontinuity for the density at the cutoff (standard errors in parentheses). 
Figure A2 - Balancing of Covariates

(a) All
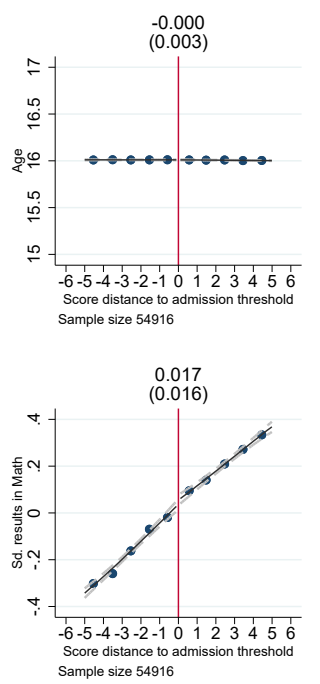
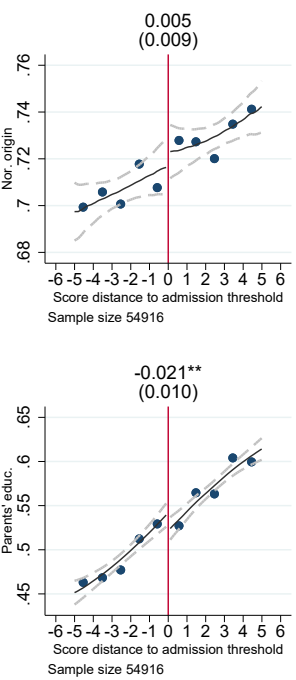
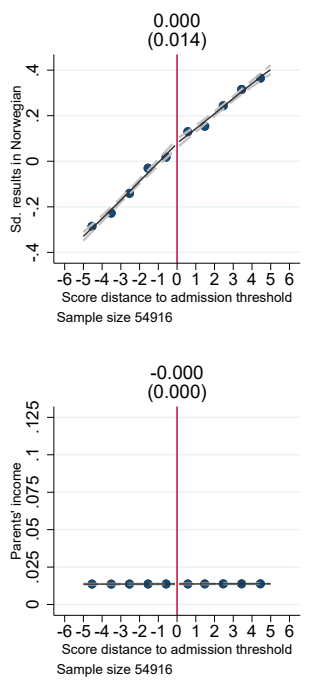

(b) Higher selectivity levels
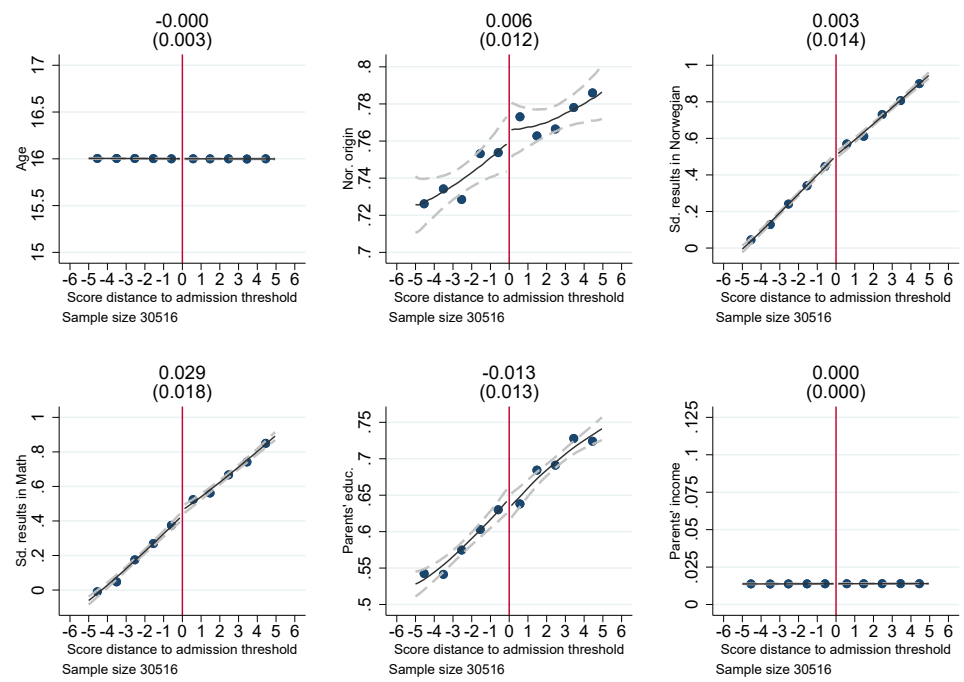

(c) Lower selectivity levels
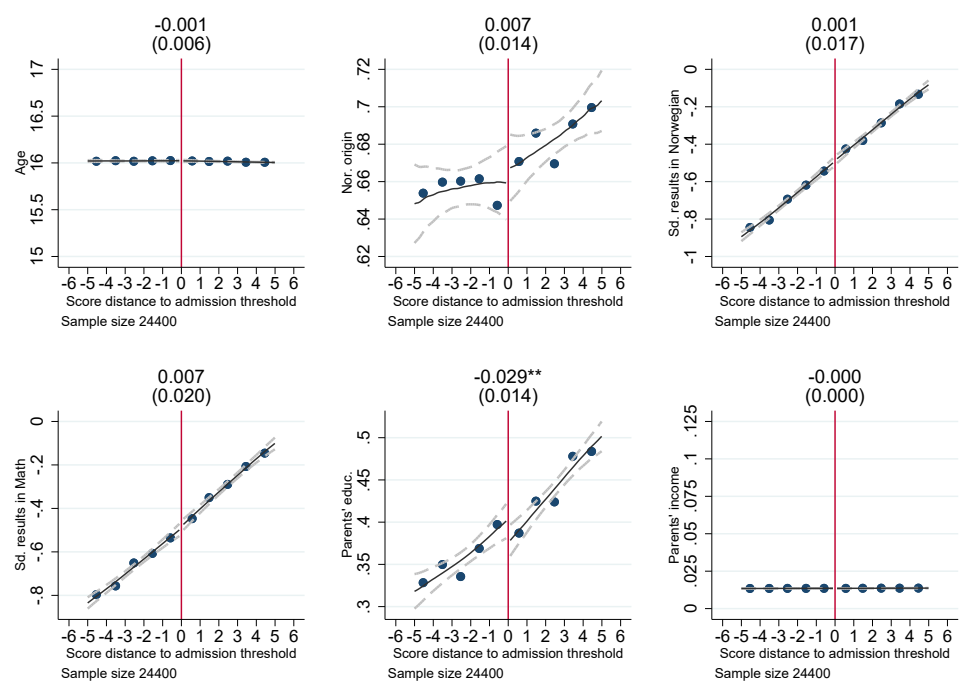

NotE: These figures plot the point estimates of $\alpha$ from equation (2) using a linear trend specification and triangular weights. The standard errors for the point estimates are clustered at individual level. The dashed lines are 95 percent confidence intervals. $* * * \mathrm{p}<0.01, * * \mathrm{p}<0.05, * \mathrm{p}<0.1$. 
Figure A3 - Prevalence of Mental Health Diagnoses and Treatments

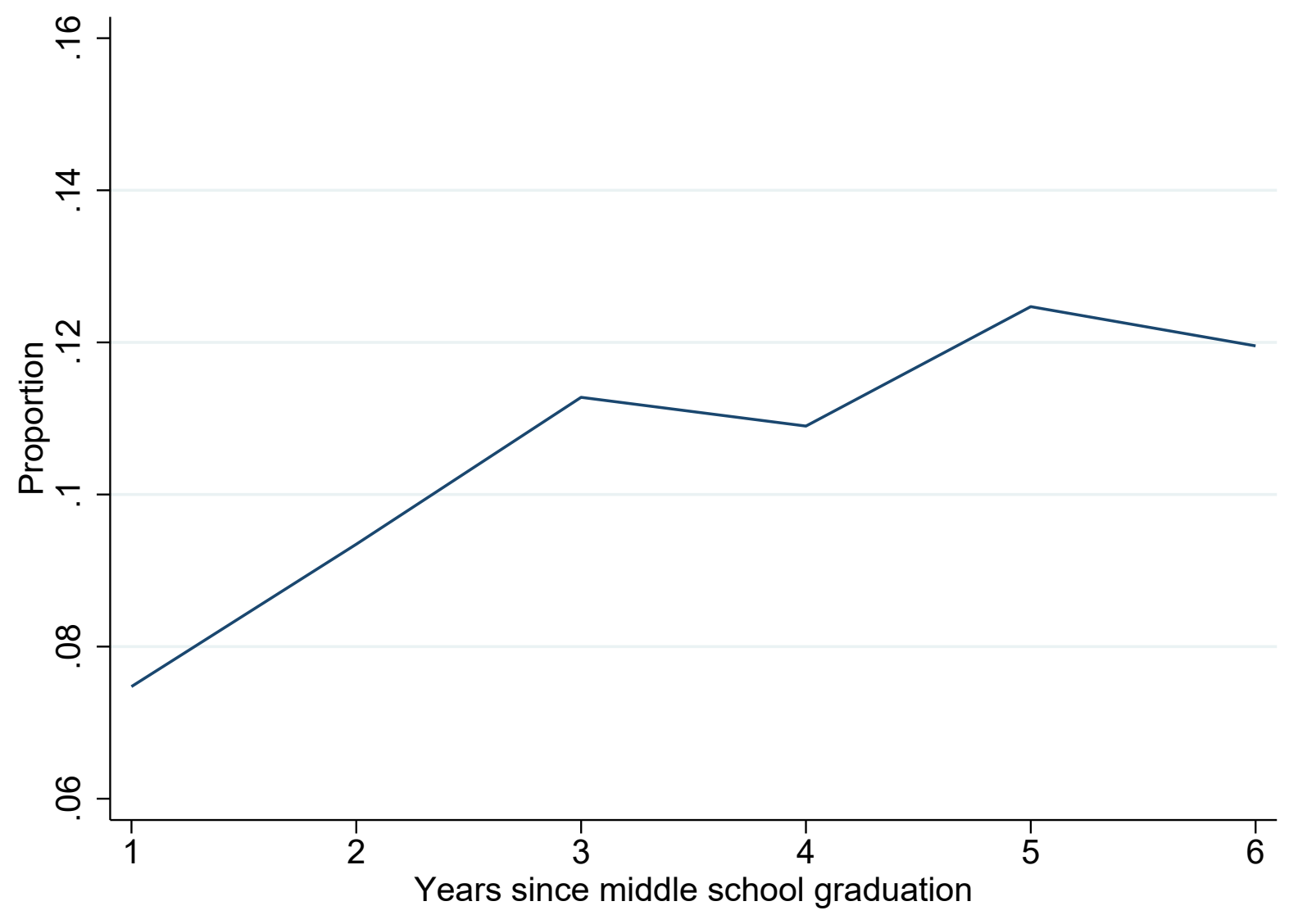


Figure A4 - Robustness to Bandwidth Selection

First stage enrollment

All

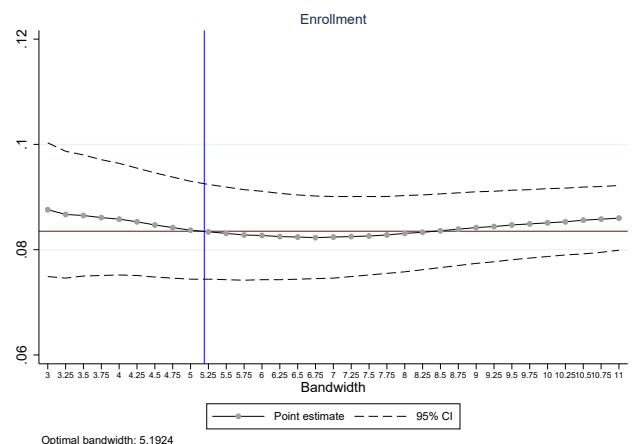

Enrollment in HE

All

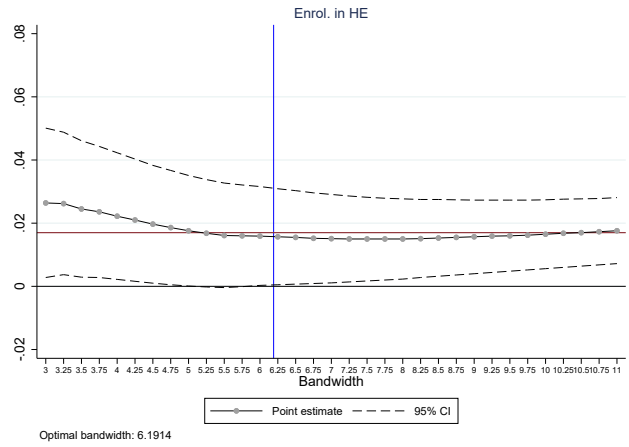

Mental health issues

All

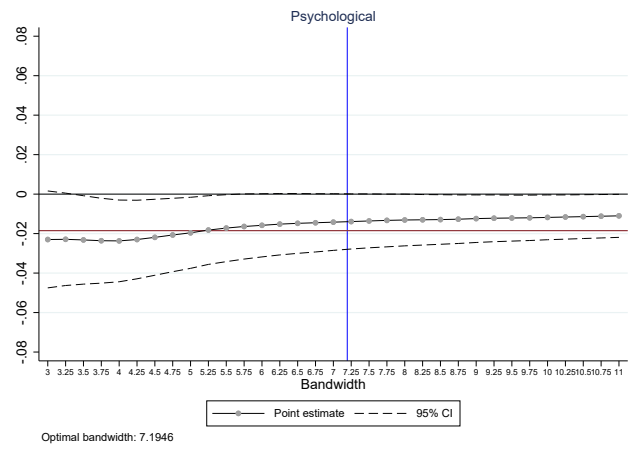

First stage enrollment

Higher selectivity levels

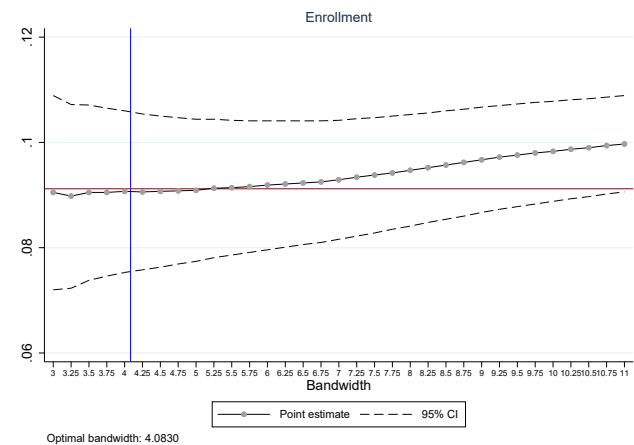

Enrollment in HE

Higher selectivity levels

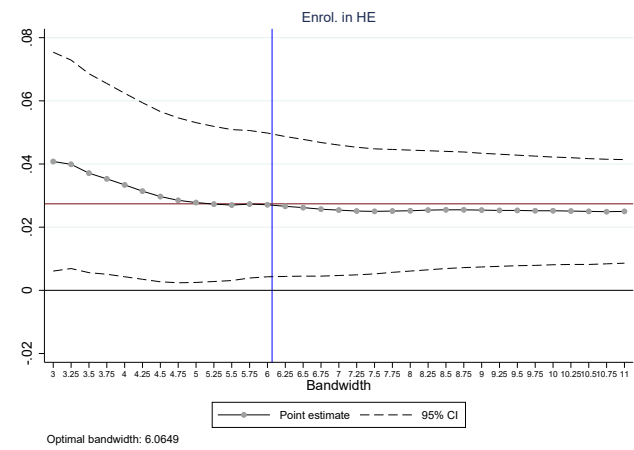

Mental health issues

Higher selectivity levels

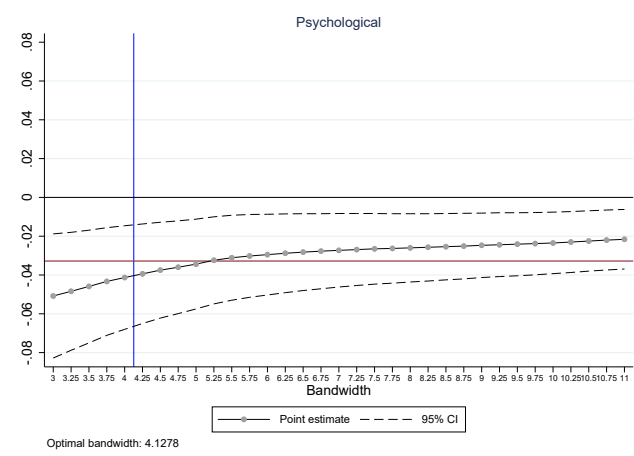

First stage enrollment

Lower selectivity levels

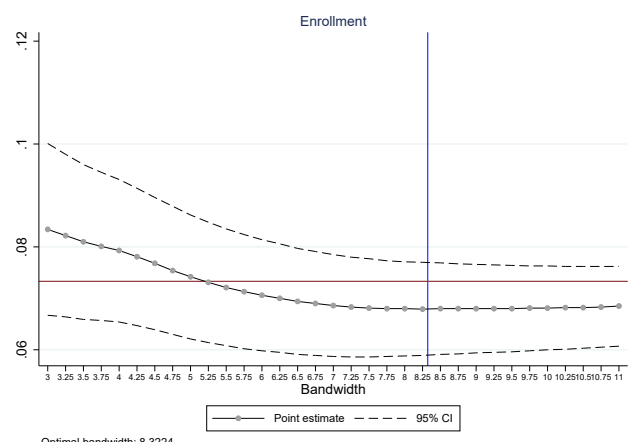

Enrollment in HE

Lower selectivity levels

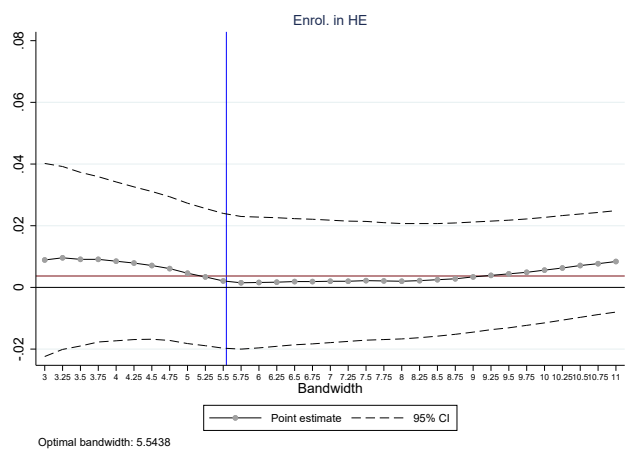

Mental health issues Lower selectivity levels

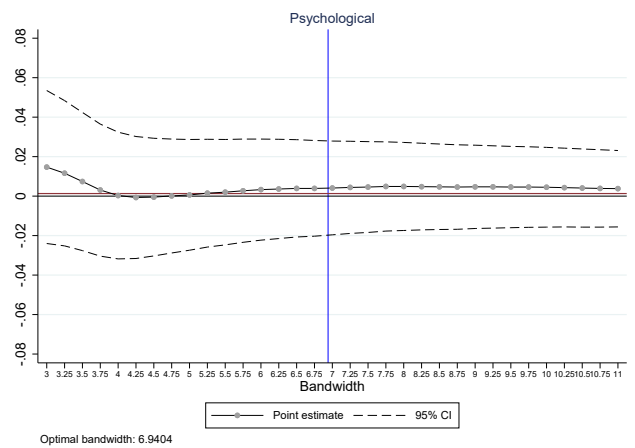

NoтE: Each point reports $\alpha$ from equation (2) with varying bandwidths. The solid red line represents the point estimates from a global linear specification with triangular weights. The vertical blue line shows the optimal bandwidth. The dashed lines are 95 percent confidence intervals. 
Table A1 - Descriptive Statistics

\begin{tabular}{|c|c|c|c|c|c|c|}
\hline & (1) & (2) & & & (5) & (6) \\
\hline & \multicolumn{2}{|c|}{ All } & \multicolumn{2}{|c|}{ Bergen area \& Oslo } & \multicolumn{2}{|c|}{ RD Sample } \\
\hline & Mean & SD & Mean & SD & Mean & SD \\
\hline Female & 0.486 & 0.500 & 0.486 & 0.500 & 0.476 & 0.499 \\
\hline Age & 16.078 & 0.906 & 16.038 & 0.649 & 16.008 & 0.154 \\
\hline Norwegian origin & 0.827 & 0.378 & 0.793 & 0.405 & 0.734 & 0.442 \\
\hline Sd. results in Norwegian & 0.000 & 0.987 & 0.112 & 0.965 & 0.081 & 0.858 \\
\hline Sd. results in Math & -0.000 & 0.985 & 0.074 & 0.982 & 0.054 & 0.916 \\
\hline \multicolumn{7}{|l|}{ Parental Background } \\
\hline Parents' educ. & 0.429 & 0.495 & 0.460 & 0.498 & 0.516 & 0.500 \\
\hline Parents' income & 1018.177 & 1052.238 & 1091.964 & 1648.111 & 1159.468 & 1355.331 \\
\hline \multicolumn{7}{|l|}{ School Environment } \\
\hline General studies & 0.398 & 0.489 & 0.462 & 0.499 & 0.541 & 0.498 \\
\hline Vocational studies & 0.509 & 0.500 & 0.475 & 0.499 & 0.405 & 0.491 \\
\hline \#Students/Teacher & 13.021 & 17.246 & 13.117 & 14.509 & 14.862 & 16.794 \\
\hline \#Students/Non-Teacher & 20.701 & 15.225 & 19.922 & 13.803 & 21.084 & 16.145 \\
\hline Share Teachers with Masters & 0.308 & 0.206 & 0.276 & 0.232 & 0.253 & 0.253 \\
\hline Teachers age & 48.308 & 4.031 & 48.122 & 4.379 & 47.470 & 4.628 \\
\hline Sh Female Teachers & 0.508 & 0.125 & 0.499 & 0.133 & 0.518 & 0.132 \\
\hline \#Stud own Program & 53.859 & 71.566 & 55.685 & 64.991 & 71.757 & 71.139 \\
\hline \multicolumn{7}{|l|}{ Peers' Characteristics } \\
\hline Peers' mean MS GPA & -0.010 & 0.693 & 0.104 & 0.703 & 0.134 & 0.715 \\
\hline Prop of female peers & 0.461 & 0.285 & 0.462 & 0.277 & 0.472 & 0.251 \\
\hline Av Inc of Peers' parents & 973147.298 & 345181.207 & 1039018.858 & 406465.607 & 1128266.195 & 447111.263 \\
\hline Education of Peers' parents & 0.405 & 0.219 & 0.432 & 0.230 & 0.485 & 0.225 \\
\hline Mental Health of Peers' parents & 0.243 & 0.090 & 0.243 & 0.086 & 0.248 & 0.078 \\
\hline \multicolumn{7}{|l|}{ Education } \\
\hline HS graduation & 0.615 & 0.487 & 0.634 & 0.482 & 0.657 & 0.475 \\
\hline Enrollment in HE & 0.381 & 0.486 & 0.394 & 0.489 & 0.423 & 0.494 \\
\hline \multicolumn{7}{|l|}{ General Health } \\
\hline GP - ER cons. & 0.975 & 0.155 & 0.970 & 0.170 & 0.966 & 0.181 \\
\hline $\mathrm{Nb}$. of GP - ER cons. & 20.654 & 21.987 & 18.980 & 20.955 & 17.672 & 19.398 \\
\hline Physical health issue & 0.973 & 0.163 & 0.968 & 0.177 & 0.963 & 0.188 \\
\hline Mental health issue & 0.320 & 0.466 & 0.326 & 0.469 & 0.314 & 0.464 \\
\hline \multicolumn{7}{|l|}{ Mental Health Disorders } \\
\hline Depression/Anxiety & 0.220 & 0.414 & 0.232 & 0.422 & 0.223 & 0.416 \\
\hline Substance Use & 0.053 & 0.223 & 0.057 & 0.232 & 0.052 & 0.222 \\
\hline ADHD & 0.041 & 0.199 & 0.035 & 0.185 & 0.031 & 0.174 \\
\hline Other Psychological & 0.155 & 0.361 & 0.153 & 0.360 & 0.143 & 0.350 \\
\hline $\mathrm{N}$ & 312267 & & 41306 & & 19932 & \\
\hline
\end{tabular}

NotE: Means and (standard deviations) of background, school environment, education, and health during the period studied (i.e., $10^{\text {th }}$ graders completing middle school between 2006 and 2010). The table includes three samples: all students completing the $10^{\text {th }}$ grade in Norway between 2006 and 2010, students completing the $10^{\text {th }}$ grade in the county of Hordaland (where the city of Bergen is located) between 2006 and 2010 and in Oslo in 2009 and 2010, and our regression discontinuity $(\mathrm{RD})$ sample. 


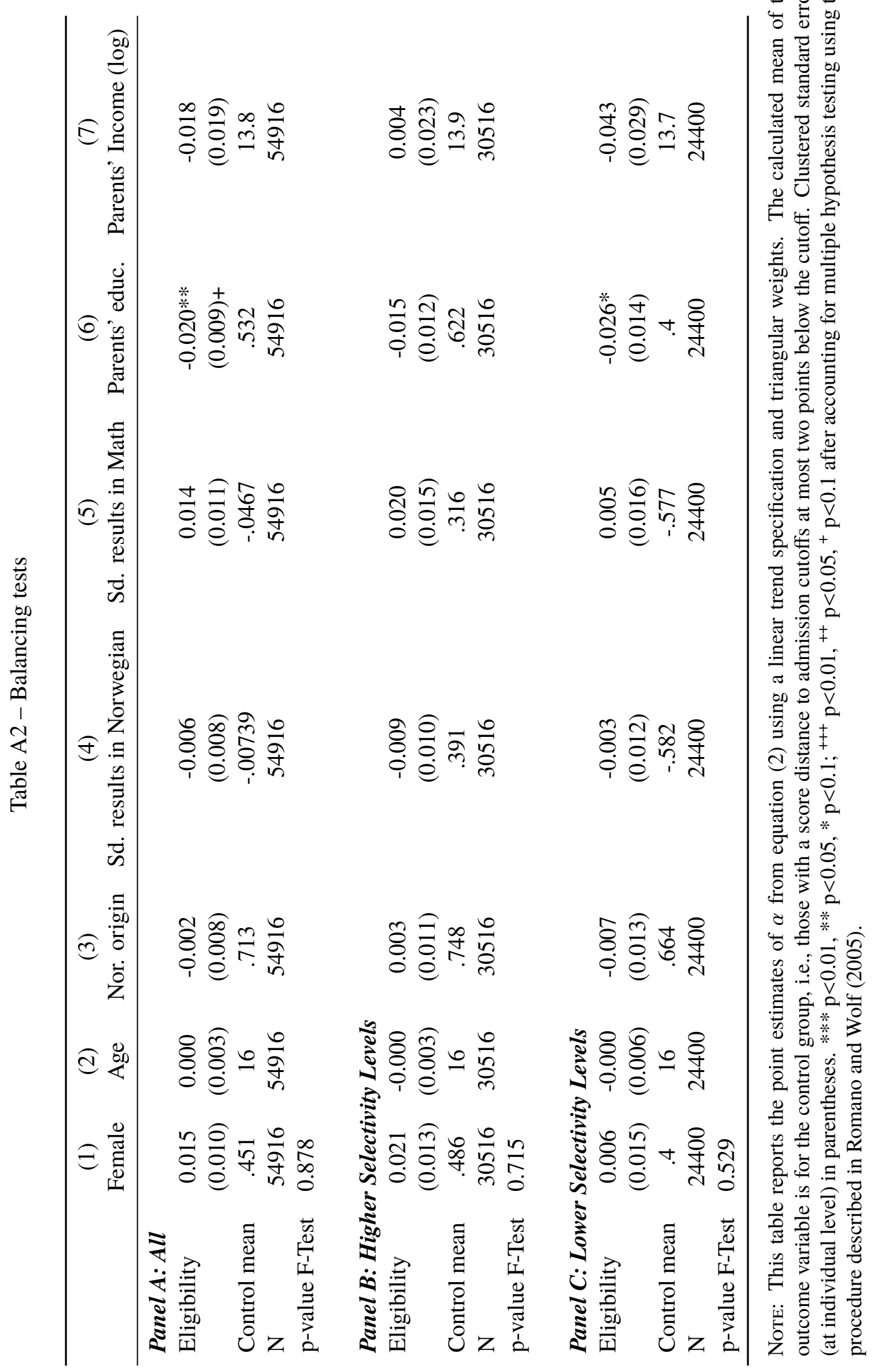


Table A3 - Local Average Treatment Effects

\begin{tabular}{|c|c|c|c|c|}
\hline & $\begin{array}{l}\text { (1) } \\
\text { High School } \\
\text { Graduation }\end{array}$ & $\begin{array}{c}(2) \\
\text { Enrollment } \\
\text { in } \mathrm{HE}\end{array}$ & $\begin{array}{c}(3) \\
\text { GR - ER } \\
\text { cons. }\end{array}$ & $\begin{array}{l}\text { (4) } \\
\text { Mental health } \\
\text { issue }\end{array}$ \\
\hline \multicolumn{5}{|l|}{ Panel A: All } \\
\hline Enrollment & $\begin{array}{c}0.280 * * * \\
(0.103)^{+++}\end{array}$ & $\begin{array}{c}0.191 * \\
(0.104)^{+}\end{array}$ & $\begin{array}{l}-0.041 \\
(0.044)\end{array}$ & $\begin{array}{l}-0.208^{*} \\
(0.107)^{+}\end{array}$ \\
\hline $\mathrm{N}$ & 54916 & 54916 & 54916 & 54916 \\
\hline \multicolumn{5}{|c|}{ Panel B: Higher selectivity Levels } \\
\hline Enrollment & $\begin{array}{c}0.348^{* * *} \\
(0.127)^{+++}\end{array}$ & $\begin{array}{c}0.292^{* *} \\
(0.139)^{++}\end{array}$ & $\begin{array}{l}-0.032 \\
(0.057)\end{array}$ & $\begin{array}{l}-0.356^{* * *} \\
(0.129)^{+++}\end{array}$ \\
\hline $\mathrm{N}$ & 30516 & 30516 & 30516 & 30516 \\
\hline \multicolumn{5}{|c|}{ Panel C: Lower selectivity Levels } \\
\hline Enrollment & $\begin{array}{c}0.208 \\
(0.176)\end{array}$ & $\begin{array}{c}0.055 \\
(0.155)\end{array}$ & $\begin{array}{c}-0.064 \\
(0.071)\end{array}$ & $\begin{array}{c}0.025 \\
(0.191)\end{array}$ \\
\hline $\mathrm{N}$ & 24400 & 24400 & 24400 & 24400 \\
\hline
\end{tabular}

NotE: This table reports the point estimates when instrumenting enrollment in a higher-ranked school by eligibility for enrollment, using a linear trend specification and triangular weights. Clustered standard errors (at individual level) in parentheses. $* * * \mathrm{p}<0.01,{ }^{*} \mathrm{p}<0.05,{ }^{*} \mathrm{p}<0.1{ }^{+++} \mathrm{p}<0.01,{ }^{++} \mathrm{p}<0.05,{ }^{+} \mathrm{p}<0.1$ after accounting for multiple hypothesis testing using the procedure described in Romano and Wolf (2005). 
Table A4 - Classification of Mental Health Conditions

\begin{tabular}{|c|c|}
\hline \multicolumn{2}{|c|}{ Mental Health Condition Grouping } \\
\hline \multirow[t]{4}{*}{ Anxiety } & P01 Feeling anxious/nervous/tense \\
\hline & P02 Acute stress reaction \\
\hline & P06 Sleep disturbance \\
\hline & P74 Anxiety disorder/anxiety state \\
\hline \multirow[t]{3}{*}{ Depression } & P03 Feeling depressed \\
\hline & P76 Depressive disorder \\
\hline & P77 Suicide/suicide attempt \\
\hline \multirow[t]{5}{*}{ Substance Use } & P15 Chronic alcohol abuse \\
\hline & P16 Acute alcohol abuse \\
\hline & P17 Tobacco abuse \\
\hline & P18 Medication abuse \\
\hline & P19 Drug abuse \\
\hline Hyperkinetic Disorders & P81 Hyperkinetic disorder \\
\hline \multirow[t]{29}{*}{ Other } & P04 Feeling/behaving irritable/angry \\
\hline & P07 Sexual desire reduced \\
\hline & P08 Sexual fulfilment reduced \\
\hline & P09 Sexual preference concern \\
\hline & P10 Stammering/stuttering/tic \\
\hline & P11 Eating problem in child \\
\hline & P12 Bedwetting/enuresis \\
\hline & P13 Encopresis/bowel training problem \\
\hline & P20 Memory disturbance \\
\hline & P22 Child behaviour symptom/complaint \\
\hline & P23 Adolescent behav. Symptom/complt. \\
\hline & P24 Specific learning problem \\
\hline & P25 Phase of life problem adult \\
\hline & P27 Fear of mental disorder \\
\hline & P28 Limited function/disability (p) \\
\hline & P29 Psychological symptom/complt other \\
\hline & P70 Dementia \\
\hline & P71 Organic psychosis other \\
\hline & P72 Schizophrenia \\
\hline & P73 Affective psychosis \\
\hline & P75 Somatization disorder \\
\hline & P78 Neuraesthenia/surmenage \\
\hline & P79 Phobia/compulsive disorder \\
\hline & P80 Personality disorder \\
\hline & P82 Post-traumatic stress disorder \\
\hline & P85 Mental retardation \\
\hline & P86 Anorexia nervosa/bulimia \\
\hline & P98 Psychosis NOS/other \\
\hline & P99 Psychological disorders, other \\
\hline
\end{tabular}

Note: This table presents the grouping of mental health problems based on the ICPC-02 diagnoses. 
Table A5 - Reduced Form Estimates: Mental Health Impacts During and After High School Years

\begin{tabular}{lcc}
\hline & $(1)$ & $(2)$ \\
& High School Years & Post-High School Years \\
\hline Panel A: All & & \\
Eligibility $(\alpha)$ & 0.004 & $-0.018^{* *}$ \\
& $(0.007)$ & $(0.008)^{++}$ \\
Control Mean & .182 & .239 \\
N & 54916 & 54916 \\
P-Value: HA: $\alpha_{\text {col } 1}<\alpha_{\text {col } 2}$ & 0.008 & \\
& & \\
Panel B: Higher Levels of Selectivity & $-0.027^{* * *}$ \\
Eligibility $(\alpha)$ & -0.006 & $(0.010)^{++}$ \\
& $(0.009)$ & .211 \\
Control Mean & .155 & 30516 \\
N & 30516 & \\
P-Value: HA: $\alpha_{\text {col } 1}<\alpha_{\text {col2 }}$ & 0.036 & \\
& & -0.006 \\
Panel C: Lower Levels Selectivity & & $(0.013)$ \\
Eligibility $(\alpha)$ & 0.018 & .279 \\
& $(0.012)$ & 24400 \\
Control Mean & .220 & \\
N & 24400 & \\
P-Value: HA: $\alpha_{\text {col } 1}<\alpha_{\text {col2 }}$ & 0.048 & \\
\hline
\end{tabular}

Note: This table reports the point estimates of $\alpha$ from equation (2) using a linear trend specification and triangular weights. The calculated mean of the outcome variable is for the control group, i.e., those with a score distance to admission cutoffs at most two points below the cutoff. Clustered standard errors (at individual level) in parentheses. *** $\mathrm{p}<0.01, * * \mathrm{p}<0.05,{ }^{*} \mathrm{p}<0.1{ }^{+++} \mathrm{p}<0.01,{ }^{++} \mathrm{p}<0.05,{ }^{+} \mathrm{p}<0.1$ after accounting for multiple hypothesis testing using the procedure described in Romano and Wolf (2005). 


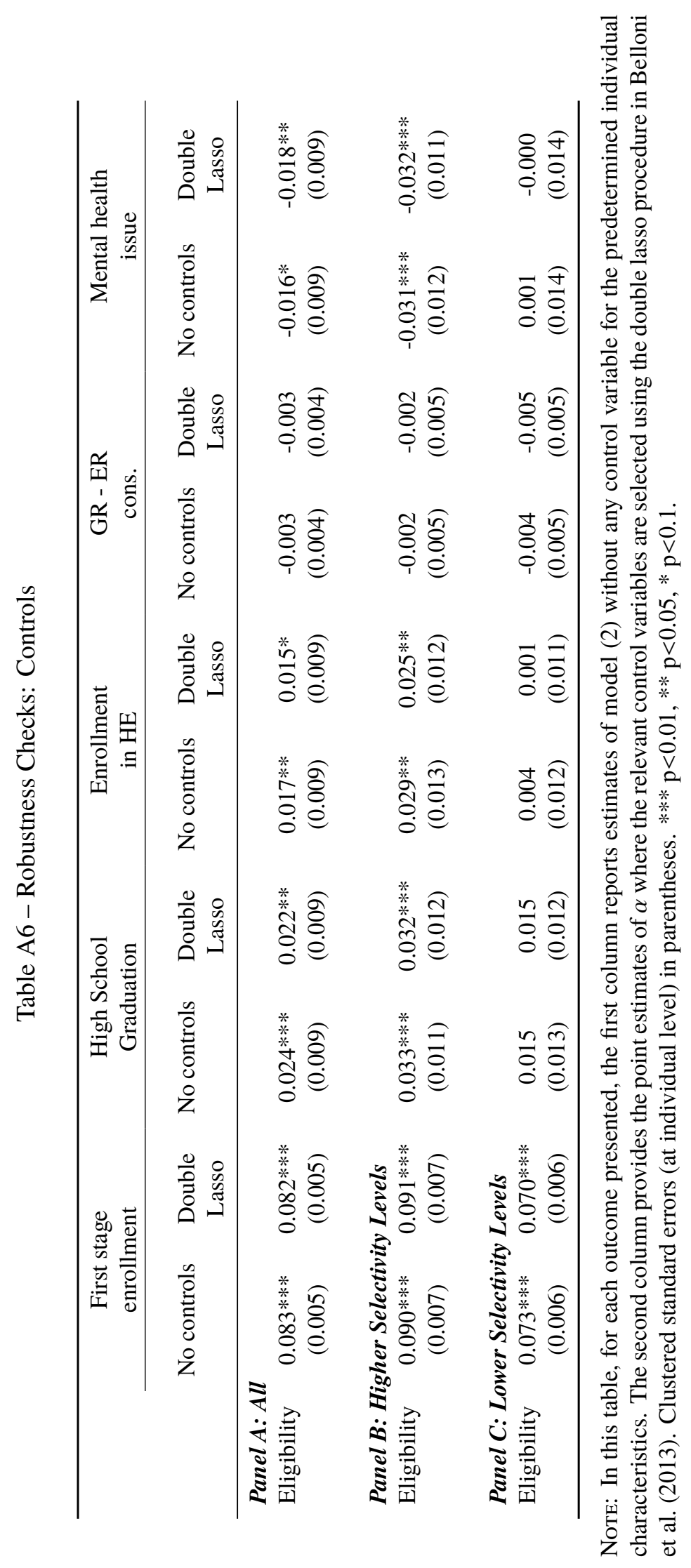




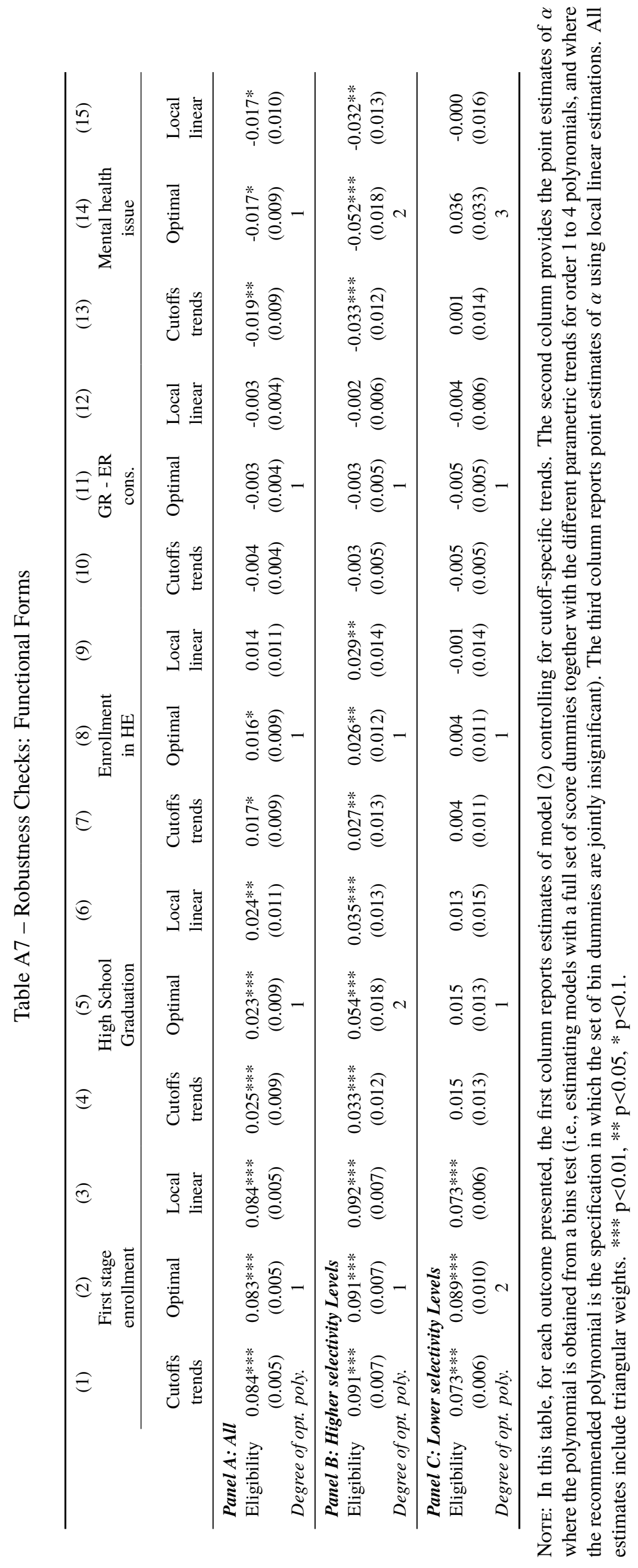




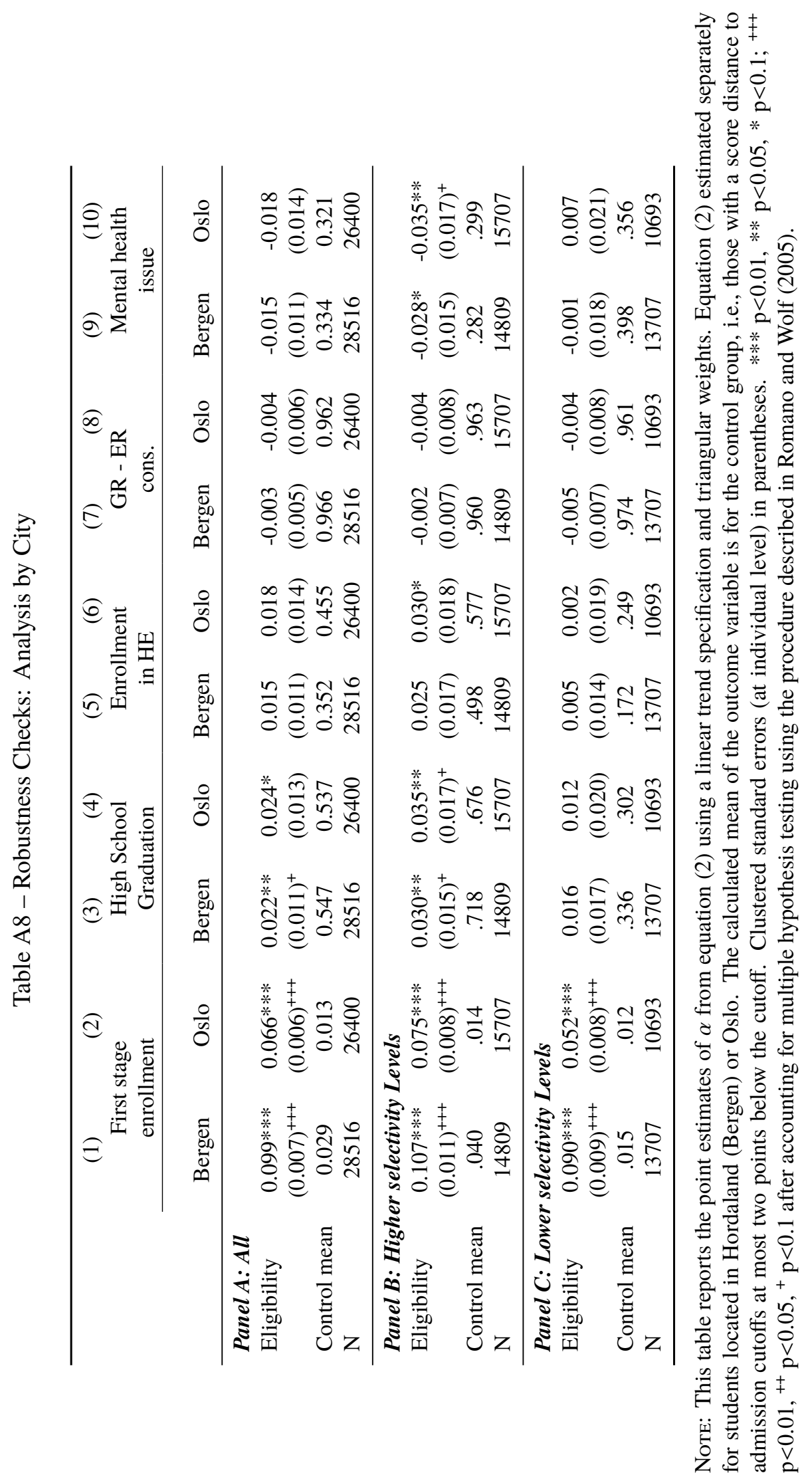


Table A9 - Heterogeneity Analysis by Student Gender and Social Background

\begin{tabular}{|c|c|c|c|c|c|}
\hline & $\begin{array}{l}\text { (1) } \\
\text { First stage } \\
\text { enrollment }\end{array}$ & $\begin{array}{c}(2) \\
\text { High School } \\
\text { Graduation }\end{array}$ & $\begin{array}{c}\text { (3) } \\
\text { Enrollment } \\
\text { in HE }\end{array}$ & $\begin{array}{c}(4) \\
\text { GR - ER } \\
\text { cons. }\end{array}$ & $\begin{array}{c}(5) \\
\text { Mental health } \\
\text { issue }\end{array}$ \\
\hline \multicolumn{6}{|l|}{ Panel A: Girls } \\
\hline Eligibility & $\begin{array}{c}0.076 * * * \\
(0.007)^{+++}\end{array}$ & $\begin{array}{c}0.019 \\
(0.013)\end{array}$ & $\begin{array}{c}0.010 \\
(0.013)\end{array}$ & $\begin{array}{l}-0.001 \\
(0.004)\end{array}$ & $\begin{array}{l}-0.032 * * \\
(0.014)^{++}\end{array}$ \\
\hline Control mean & 0.023 & 0.620 & 0.481 & 0.986 & 0.386 \\
\hline $\mathrm{N}$ & 25561 & 25561 & 25561 & 25561 & 25561 \\
\hline \multicolumn{6}{|l|}{ Panel B: Boys } \\
\hline Eligibility & $\begin{array}{c}0.089 * * * \\
(0.006)^{+++}\end{array}$ & $\begin{array}{c}0.029^{* *} \\
(0.011)^{++}\end{array}$ & $\begin{array}{c}0.022 * \\
(0.011)^{+}\end{array}$ & $\begin{array}{l}-0.005 \\
(0.006)\end{array}$ & $\begin{array}{l}-0.005 \\
(0.012)\end{array}$ \\
\hline Control mean & 0.020 & 0.478 & 0.338 & 0.947 & 0.279 \\
\hline $\mathrm{N}$ & 29355 & 29355 & 29355 & 29355 & 29355 \\
\hline \multicolumn{6}{|c|}{ Panel C: Parents with higher education } \\
\hline Eligibility & $\begin{array}{c}0.099 * * * \\
(0.007)^{+++}\end{array}$ & $\begin{array}{c}0.012 \\
(0.012)\end{array}$ & $\begin{array}{c}0.012 \\
(0.012)\end{array}$ & $\begin{array}{l}-0.002 \\
(0.005)\end{array}$ & $\begin{array}{l}-0.015 \\
(0.012)\end{array}$ \\
\hline Control mean & 0.026 & 0.631 & 0.471 & 0.958 & 0.311 \\
\hline $\mathrm{N}$ & 29478 & 29478 & 29478 & 29478 & 29478 \\
\hline \multicolumn{6}{|c|}{ Panel D: Parents without higher education } \\
\hline Eligibility & $\begin{array}{c}0.064 * * * \\
(0.006)^{+++}\end{array}$ & $\begin{array}{c}0.035^{* * *} \\
(0.013)^{+++}\end{array}$ & $\begin{array}{l}0.020^{*} \\
(0.012)\end{array}$ & $\begin{array}{l}-0.005 \\
(0.005)\end{array}$ & $\begin{array}{l}-0.020 \\
(0.013)\end{array}$ \\
\hline Control mean & 0.016 & 0.444 & 0.327 & 0.971 & 0.346 \\
\hline $\mathrm{N}$ & 25438 & 25438 & 25438 & 25438 & 25438 \\
\hline \multicolumn{6}{|c|}{ Panel E: high parental income } \\
\hline Eligibility & $\begin{array}{c}0.097 * * * \\
(0.007)^{+++}\end{array}$ & $\begin{array}{l}0.024 * * \\
(0.012)^{+}\end{array}$ & $\begin{array}{c}0.006 \\
(0.012)\end{array}$ & $\begin{array}{l}-0.007 \\
(0.006)\end{array}$ & $\begin{array}{l}-0.026^{* *} \\
(0.012)^{++}\end{array}$ \\
\hline Control mean & 0.023 & 0.634 & 0.481 & 0.962 & 0.292 \\
\hline $\mathrm{N}$ & 27738 & 27738 & 27738 & 27738 & 27738 \\
\hline \multicolumn{6}{|c|}{ Panel F: low parental income } \\
\hline Eligibility & $\begin{array}{c}0.068^{* * *} \\
(0.006)^{+++}\end{array}$ & $\begin{array}{l}0.021 * \\
(0.012)\end{array}$ & $\begin{array}{c}0.025^{* *} \\
(0.012)^{++}\end{array}$ & $\begin{array}{c}0.001 \\
(0.005)\end{array}$ & $\begin{array}{l}-0.010 \\
(0.013)\end{array}$ \\
\hline Control mean & 0.020 & 0.455 & 0.327 & 0.966 & 0.361 \\
\hline $\mathrm{N}$ & 27178 & 27178 & 27178 & 27178 & 27178 \\
\hline
\end{tabular}

Note: This table reports the point estimates of $\alpha$ from equation (2) using a linear trend specification and triangular weights. The calculated mean of the outcome variable is for the control group, i.e., those with a score distance to admission cutoffs at most two points below the cutoff. Clustered standard errors (at individual level) in parentheses. $* * * \mathrm{p}<0.01, * * \mathrm{p}<0.05,{ }^{*} \mathrm{p}<0.1{ }^{+++} \mathrm{p}<0.01,{ }^{++} \mathrm{p}<0.05,{ }^{+} \mathrm{p}<0.1$ after accounting for multiple hypothesis testing using the procedure described in Romano and Wolf (2005). 
Appendix B 


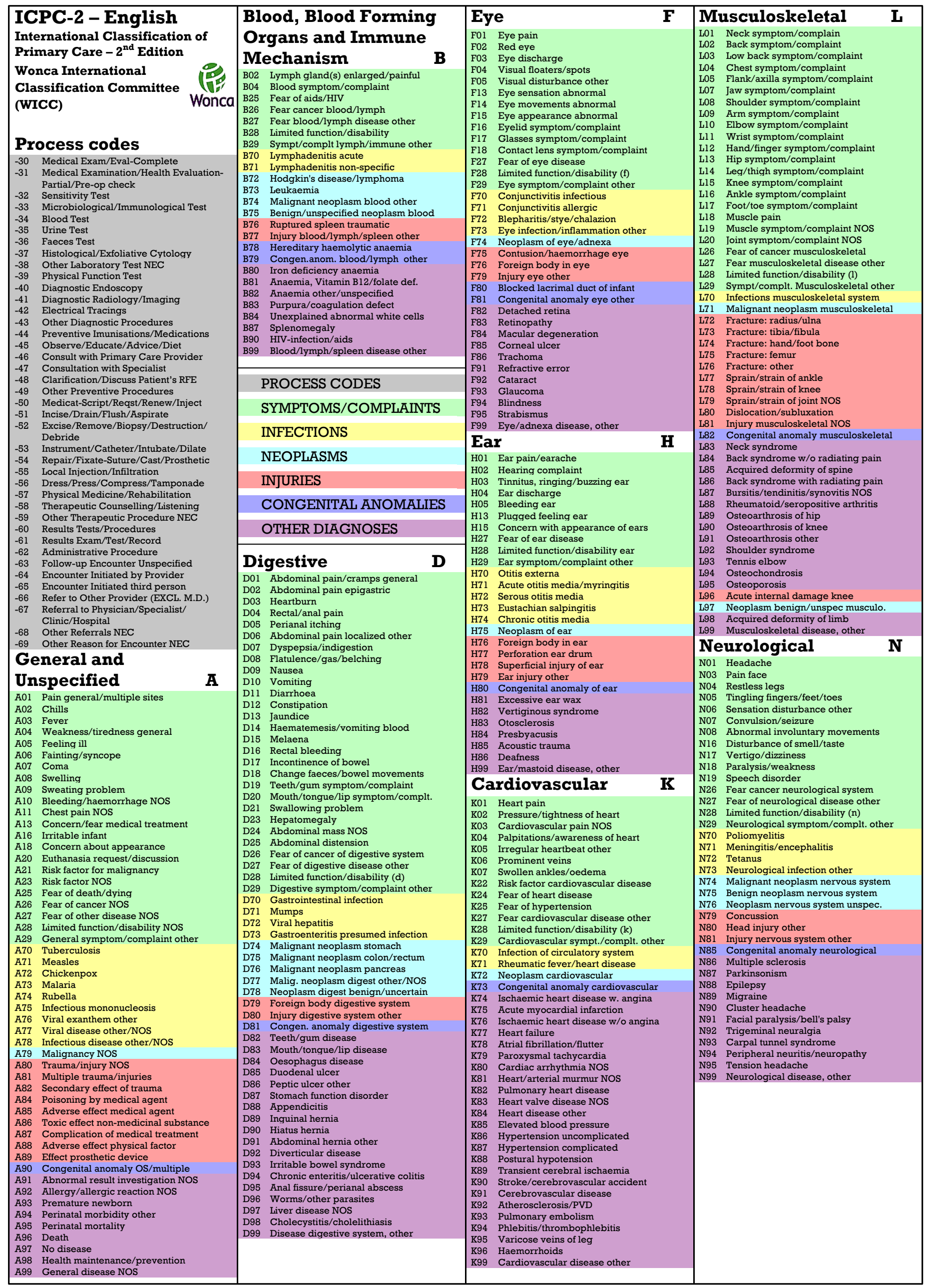




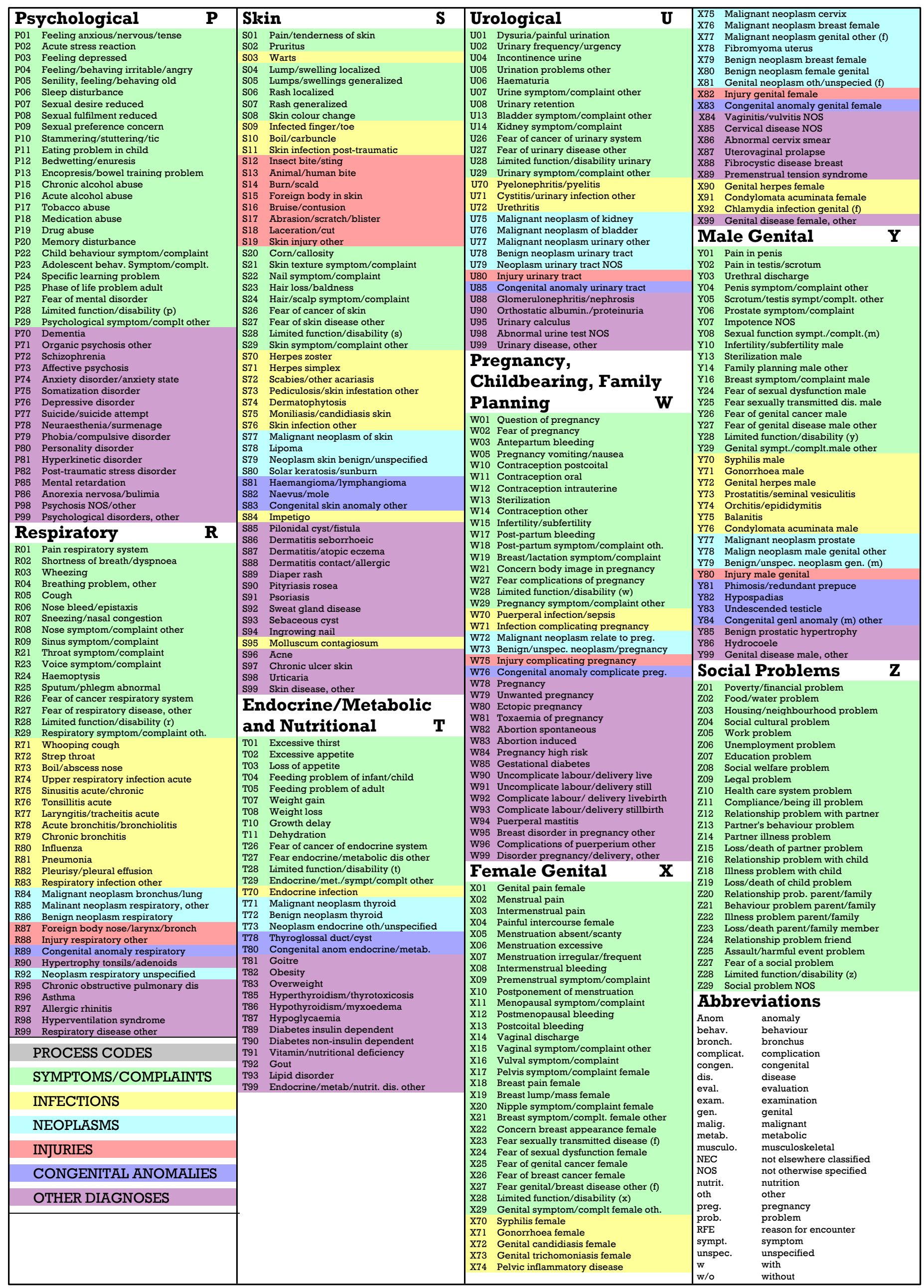

